\title{
Epidemiology of Systemic Mycoses in the COVID-19 Pandemic
}

\author{
María Guadalupe Frías-De-León ${ }^{1} \mathbb{D}$, Rodolfo Pinto-Almazán ${ }^{1,2} \mathbb{D}$, Rigoberto Hernández-Castro ${ }^{3}$, \\ Eduardo García-Salazar 1,4 , Patricia Meza-Meneses ${ }^{4,5}$, Carmen Rodríguez-Cerdeira 6,7,8 (D), Roberto Arenas ${ }^{6,9}$, \\ Esther Conde-Cuevas ${ }^{4}$, Gustavo Acosta-Altamirano ${ }^{1}$ and Erick Martínez-Herrera ${ }^{1,2,6, *(D)}$
}

1 Unidad de Investigación, Hospital Regional de Alta Especialidad de Ixtapaluca, Ciudad de México PC 56530, Estado de México, Mexico; magpefrias@gmail.com (M.G.F.-D.-L.); rodolfopintoalmazan@gmail.com (R.P.-A.); eduardogs_01@hotmail.com (E.G.-S.); mq9903@live.com.mx (G.A.-A.)

2 Sección de Estudios de Posgrado e Investigación, Escuela Superior de Medicina, Instituto Politécnico Nacional, Plan de San Luis y Díaz Mirón s/n, Col. Casco de Santo Tomas, Alcaldía Miguel Hidalgo, Ciudad de México PC 11340, Estado de México, Mexico

3 Departamento de Ecología de Agentes Patógenos, Hospital General “Dr. Manuel Gea González”, Ciudad de México PC 14080, Estado de México, Mexico; rigo37@gmail.com

4 Maestría en Ciencias de la Salud, Escuela Superior de Medicina, Instituto Politécnico Nacional, Plan de San Luis y Díaz Mirón s/n, Col. Casco de Santo Tomas, Alcaldía Miguel Hidalgo,

Ciudad de México PC 11340, Estado de México, Mexico; patricia_meza@ymail.com (P.M.-M.); condeesther999@gmail.com (E.C.-C.)

\section{check for}

updates

Citation: Frías-De-León, M.G.; Pinto-Almazán, R.; HernándezCastro, R.; García-Salazar, E.; Meza-Meneses, P.; RodríguezCerdeira, C.; Arenas, R.; CondeCuevas, E.; Acosta-Altamirano, G.; Martínez-Herrera, E. Epidemiology of Systemic Mycoses in the COVID-19 Pandemic. J. Fungi 2021, 7, 556. https://doi.org/10.3390/jof7070556

Academic Editor: Joshua

Daniel Nosanchuk

Received: 4 June 2021

Accepted: 7 July 2021

Published: 13 July 2021

Publisher's Note: MDPI stays neutral with regard to jurisdictional claims in published maps and institutional affiliations.
5 Servicio de Infectología, Hospital Regional de Alta Especialidad de Ixtapaluca, Ciudad de México PC 56530, Estado de México, Mexico

6 Efficiency, Quality, and Costs in Health Services Research Group (EFISALUD), Galicia Sur Health Research Institute (IIS Galicia Sur), SERGAS-UVIGO, PC 36213 Vigo, Spain; carmencerdeira33@gmail.com (C.R.-C.); rarenas98@gmail.com (R.A.)

7 Dermatology Department, Hospital Vithas Ntra. Sra. de Fátima and University of Vigo, PC 36206 Vigo, Spain

8 Campus Universitario, University of Vigo, PC 36310 Vigo, Spain

9 Sección de Micología, Hospital General "Dr. Manuel Gea González", Ciudad de México PC 14080, Estado de México, Mexico

* Correspondence: erickmartinez_69@hotmail.com; Tel.: +52-555-972-9800

Abstract: The physiopathologic characteristics of COVID-19 (high levels of inflammatory cytokines and T-cell reduction) promote fungal colonization and infection, which can go unnoticed because the symptoms in both diseases are very similar. The objective of this work was to study the current epidemiology of systemic mycosis in COVID-19 times. A literature search on the subject (January 2020-February 2021) was performed in PubMed, Embase, Cochrane Library, and LILACS without language restrictions. Demographic data, etiological agent, risk factors, diagnostic methods, antifungal treatment, and fatality rate were considered. Eighty nine publications were found on co-infection by COVID-19 and pneumocystosis, candidiasis, aspergillosis, mucormycosis, coccidioidomycosis, or histoplasmosis. In general, the co-infections occurred in males over the age of 40 with immunosuppression caused by various conditions. Several species were identified in candidiasis and aspergillosis co-infections. For diagnosis, diverse methods were used, from microbiological to molecular. Most patients received antifungals; however, the fatality rates were $11-100 \%$. The latter may result because the clinical picture is usually attributed exclusively to SARS-CoV-2, preventing a clinical suspicion for mycosis. Diagnostic tests also have limitations beginning with sampling. Therefore, in the remainder of the pandemic, these diagnostic limitations must be overcome to achieve a better patient prognosis.

Keywords: co-infection; COVID-19; systemic mycoses; pneumocystosis; candidiasis; aspergillosis; mucormycosis; endemic mycosis

\section{Introduction}

SARS-CoV-2 is a betacoronavirus that causes the "2019 coronavirus disease" (COVID-19). Since the World Health Organization (WHO) declared a pandemic in March 2020, the 
world has been facing a health crisis that has involved significant challenges in diagnosing, treating, and preventing COVID-19 and its complications. As of 21 March 2021, it has affected 122,524,424 people in 222 countries resulting in the deaths of 2,703,620 individuals, showing an overall fatality rate of $2.2 \%$ [1]. The clinical course and progression of SARS$\mathrm{CoV}-2$ infection is variable and can lead to respiratory failure [2]. Clinical presentations of COVID-19 include fever $\left(\geq 38{ }^{\circ} \mathrm{C}\right)$, cough, shortness of breath, loss of smell, chills, headache, and joint pain, among the most frequently reported. In most cases, the disease is asymptomatic or with mild to moderate symptomatology (80-85\%) [3]. However, the disease can evolve to more severe clinical pictures in some patients, putting their lives at risk.

Reports indicate that the overall host state and the presence of comorbidities facilitate the spread of the virus and tropism of target organs with angiotensin-converting enzyme 2 (ACE2) receptors and increased production of interleukin (IL)-6, IL-1, and tumor necrosis factor (TNF)- $\alpha$ in severe cases [2]. In the case of the disease requiring hospitalization, it is characterized by pneumonia, lymphopenia, and cytokine release syndrome (CRS), which trigger an exaggerated immune response that causes damage at the local and systemic level. The previous occurs because, after the virus enters the cells and releases its genetic material (RNA), it is recognized by innate immunity receptors located intracellularly. Receptors such as the Toll 7 (TLR7), retinoic acid-inducible gene I (RIG-1), and melanoma differentiationassociated protein 5 (MDA-5), activate a signaling cascade, leading to the expression of interferon (IFN) type I ( $\alpha$ and $\beta$ ), the objective of which is to interfere with viral replication. On the other hand, viral antigens can be processed by antigen-presenting cells through their major histicompatibility complex (MHC)-I to T cell receptor (TCR) of T CD8+ lymphocyte, which involves releasing their proteolytic enzymes (cytotoxicity). At the same time, the cytokine storm begins (an increase of IL-1B, IL-6, IL-7, IL-8, IL-9, IL-10, and TNF- $\alpha$ [2-4].

In mild pneumonia, patients may be asymptomatic or have at least one of the following symptoms: fever (constant or intermittent), dry cough, sore throat, headache, myalgia, tiredness, or diarrhea. However, they do not present dyspnea nor hypoxia [3]. Although in most patients (81\%), the course of the disease is mild, some develop severe pneumonia, characterized by the acute respiratory distress syndrome (ARDS), refractory hypoxemia, and dyspnea. More than 50\% experience lung damage radiologically characterized by the presence of bilateral ground-glass opacities. In some cases, patients also develop damage and dysfunction of the extrapulmonary system, such as alterations in the hematological and digestive system, risk of sepsis, and septic shock, with a high mortality rate [4]. Some of these patients present patchy bilateral opacities in the lungs, leukopenia or lymphopenia, and increased serum levels of alanine aminotransferase (ALT), aspartate transaminase (AST), lactate dehydrogenase (LDH), creatine kinase myocardial band (CK-MB), C-reactive protein (CRP), and erythrocyte sedimentation rate (ESR) [5].

Approximately 5 to $30 \%$ of COVID-19 patients have been reported to become critically ill, require mechanical ventilation, and admission to the Intensive Care Unit (ICU) [2,3], which constitutes a risk factor for the development of co-infections with other bacterial, viral, or fungal pathogens. SARS-CoV-2 infection is characterized by a cytokine storm involving increased inflammatory proteins (TNF- $\alpha$, IL-6, IL-2R) and decreased anti-inflammatory proteins. The latter contributes to lung pathology and lymphopenia development (drastic decrease in T cells, CD4+ and CD8+) in patients admitted to the ICU [5]. Lymphopenia in patients with severe COVID-19 is a clinical situation that increases the risk of severe fungal infections by different fungal genera, such as Pneumocystis, Candida, and Aspergillus, as $T$ cells are the second most crucial line of defense against mycoses [6,7].

Fungal co-infections in COVID-19 patients is not a surprising situation. There are precedents that viral pneumonia, such as H1N1 and H7N9 influenza, can have co-infections caused by fungi and bacteria, and even other viruses [8-17]. During the outbreak of severe acute respiratory syndrome (SARS) detected in Guangdong, China, in November 2002, that subsequently spread to more than 30 countries, a series of autopsy cases were reported, which evidenced invasive fungal infection compatible with invasive aspergillosis in $10 \%$ of 
cases [18]. Interestingly, all infected patients were treated with high doses of corticosteroids, possibly resulting in immunosuppression that facilitated the establishment of mycoses. Another autopsy study of individuals who died of SARS confirmed fungal co-infection with the isolation of Aspergillus sp. and Mucor sp. in the upper respiratory tract and lungs. A case with multiple Aspergillus abscesses in different organs was also reported [19]. With this background, the co-infection scenario is expected to be similar in SARS-CoV-2 pneumonia.

This work analyzes the epidemiology of fungal co-infections in COVID-19 patients based on the review of publications on the subject during the first year of the pandemic.

\section{Materials and Methods}

A thorough search of publications on the subject was performed from January 1st, 2020, to 28 February 2021. The search was conducted on PubMed, Embase, Cochrane Library, and LILACS. The search words used were "fungi" OR "fungus" OR "fungal infection" OR "invasive fungal diseases" OR "pneumocystis" OR "candidiasis" OR "aspergillosis" OR "mucor" OR "histoplasmosis" OR "coccidioidomycosis" OR "co-infection" OR "secondary infection" AND “COVID-19" OR "SARS-CoV-2" OR "2019-nCoV" OR "2019 novel coronavirus" without language restrictions. Cases caused by Cryptococcus, Fusarium, Saccharomyces, and other fungi were excluded from the study due to the low number of reports. The review was performed based on the preferred reporting items for systematic reviews and meta-analyses (PRISMA) (Figure 1).

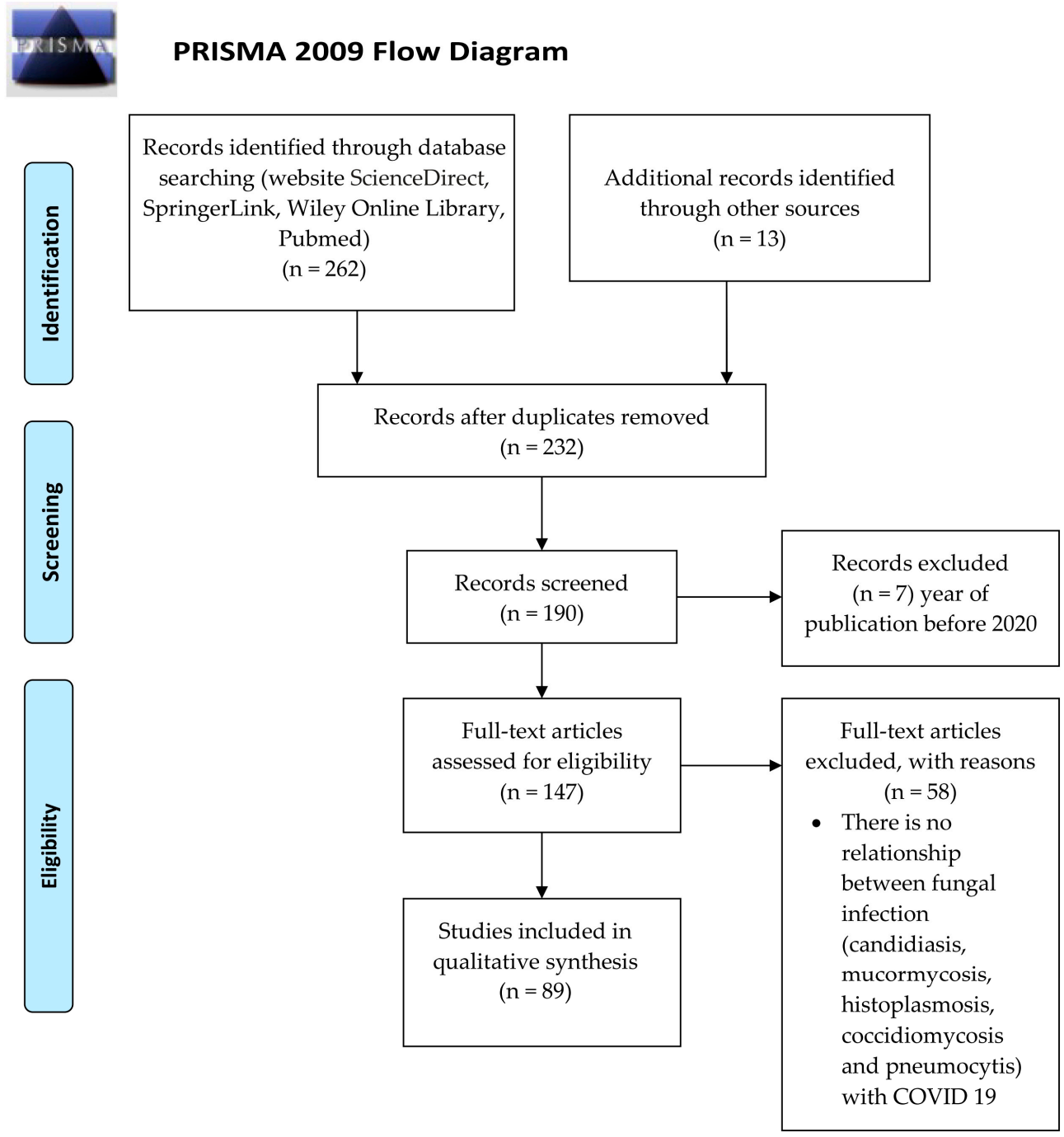

Figure 1. Flowchart of the different phases of the systematic review. 


\section{Pneumonia by Pneumocystis jirovecii and COVID-19}

During the COVID-19 pandemic, 13 publications have reported a total of 24 confirmed cases of co-infection with SARS-CoV-2 and P. jirovecii (Table 1). This co-infection has occurred in both men and women, in the age range of 11-83 years, predominantly in males over 40 years of age [20-32]. The main risk factor for developing co-infection with Pneumocystis was HIV infection with low CD4+ count, followed by immunosuppressive treatments, lymphopenia, and autoimmune disease (anti-melanoma differentiation-associated gene 5 juvenile dermatomyositis) [20-32]. Seven of these cases did not identify a typical risk factor for pneumocystosis [20]. The fungal presence was confirmed in 22 cases through different methods, such as PCR, high-performance sequencing, detection of $\beta$-D-glucan in serum, and staining techniques (Grocott and direct fluorescent antibody stain) [20-25,27-32]. Treatment of pneumocystosis in COVID-19 patients was trimethoprim-sulfamethoxazole [20-32]. However, one patient presented intolerance to this medication, so he was treated with clindamycin [26]. In five cases, prednisone/prednisolone was added to treatment with trimethoprim-sulfamethoxazole $[21,24,27,28,32]$. In one case, the patient was successfully treated with caspofungin acetate [23]. The fatality rate of COVID-19 and pneumocystosis was $33.3 \%$ [20-32]. 
Table 1. Cases of COVID-19 and Pneumocystis jirovecii co-infection.

\begin{tabular}{|c|c|c|c|c|c|}
\hline $\begin{array}{c}\text { Number of Cases/Sex/Age } \\
\text { (Years)/Country }\end{array}$ & Risk Factors & Diagnostic Method & Clinical Management & Fatality Rate (\%) & Reference \\
\hline $\begin{array}{c}10 / 8 \text { male and } 2 \text { female/average } \\
\text { between } 46-68 / \text { France }\end{array}$ & $\begin{array}{l}\text { Prolonged corticosteroid } \\
\text { treatment in } 3 \text { patients }\end{array}$ & $\begin{array}{l}\text { RT-qPCR; detection of } \\
\beta \text {-D-glucan in serum }\end{array}$ & $\begin{array}{c}\text { Cotrimoxazole in } 4 \text { patients, } 6 \text { patients } \\
\text { were not treated }\end{array}$ & 30.0 & [20] \\
\hline $1 /$ male/25/USA & $\mathrm{HIV}, \mathrm{CD} 4=32$ cells $/ \mathrm{mm}^{3}$ & $\begin{array}{l}\text { Detection of antigen in } \\
\text { respiratory secretions by } \\
\text { bronchoscopy }\end{array}$ & $\begin{array}{l}\text { Trimethoprim-sulfamethoxazole, } \\
\text { prednisone }\end{array}$ & 0.0 & [21] \\
\hline $\begin{array}{l}2 / \text { female } / 78 \text { and the other was not } \\
\text { reported/France }\end{array}$ & Lymphocytopenia & qPCR in BAL & Specific anti-Pneumocystis treatment & 100.0 & [22] \\
\hline $1 /$ female/72/China & $\begin{array}{l}\text { 30-year-old rheumatoid arthritis } \\
\text { and glucocorticoid treatment }\end{array}$ & $\begin{array}{l}\text { High troughput } \\
\text { sequencing analysis }\end{array}$ & Caspofungin acetate, glucocorticoids & 0.0 & [23] \\
\hline $1 / \mathrm{male} / 55 / \mathrm{UK}$ & HIV, CD4 422 cells $/ \mu \mathrm{L}$ & PCR multiplex & Cotrimoxazole and prednisolone & 0.0 & [24] \\
\hline $1 /$ male/ $65 /$ Italy & $\begin{array}{c}\text { Kidney transplant, } \\
\text { immunosuppressive treatment }\end{array}$ & qPCR & Trimethoprim-sulfamethoxazole & 100.0 & [25] \\
\hline 2/ND/ND/China & HIV & ND & $\begin{array}{l}\text { Clindamycin for one patient and } \\
\text { trimethoprim-sulfamethoxazole for } \\
\text { the other }\end{array}$ & 0.0 & [26] \\
\hline $1 /$ female/46/Argentina & $\begin{array}{l}\text { HIV, absolute CD } 4+\text { count } \\
67 \text { cells } / \mu \mathrm{L}\end{array}$ & $\begin{array}{l}\text { Grocott stain of a } \\
\text { sputum sample }\end{array}$ & $\begin{array}{l}\text { Ceftriaxone, azithromycin, } \\
\text { trimethoprim-sulfamethoxazole, } \\
\text { prednisone, and fluconazole }\end{array}$ & 0.0 & [27] \\
\hline $1 /$ male/52/Germany & $\begin{array}{l}\text { HIV, CD4+ } 12 \text { cells / } \mu \text { L viral load } \\
\text { of } 360,000 \text { HIV- } 1 \text { RNA copies } / m L\end{array}$ & $\begin{array}{l}\text { Pneumocystis detection in } \\
\text { BAL by a non-specified } \\
\text { method, high LDH }\end{array}$ & $\begin{array}{l}\text { Trimethoprim-sulfamethoxazol, } \\
\text { prednisone }\end{array}$ & 0.0 & [28] \\
\hline $1 /$ female/83/USA & Lymphocytopenia & qPCR of tracheal aspirate & Trimethoprim-sulfamethoxazole & 0.0 & [29] \\
\hline $1 /$ male $/ 65 /$ France & $\begin{array}{c}\text { Chemotherapy for chronic } \\
\text { lymphocytic leukemia, } \\
\text { lymphopenia }\end{array}$ & qPCR in BAL & Trimethoprim-sulfamethoxazole & 0.0 & [30] \\
\hline $1 /$ female/11/Spain & anti-MDA5 JDM & RT-PCR & Trimethoprim-sulfamethoxazole & 100.0 & [31] \\
\hline $1 /$ male/36/USA & $\begin{array}{l}\text { HIV, absolute CD4 cell count was } \\
<10 \text { cells } / \mu \mathrm{L}\end{array}$ & DFA and PCR & $\begin{array}{c}\text { Trimethoprim-sulfamethoxazole } \\
\text { and prednisone }\end{array}$ & 100.0 & [32] \\
\hline
\end{tabular}

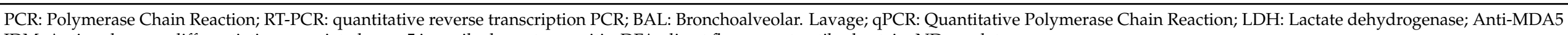
JDM: Anti-melanoma differentiation-associated gene 5 juvenile dermatomyositis; DFA: direct fluorescent antibody stain; ND: no data. 


\section{Candidiasis and COVID-19}

In the first year of the COVID-19 pandemic, 29 articles on co-infection by SARS-CoV-2 and Candida spp. have been published (Table 2). Co-infections by Candida have been observed in both women and men, but predominantly in men over the age of 40 [33-61]. The predisposing factors of candidiasis were multiple, including mechanical ventilation, placement of a central venous catheter, diabetes mellitus, antibiotics treatment, hospitalization time, anti-inflammatory treatment, and cancer [33-61]. Other less common risk factors were asthma, HIV, and surgery, among others [34-36,38,41,45,47-50,52,56,60]. The diagnosis was performed through culture, PCR, sequencing, and MALDI-TOF [33-37,39-61]. The most identified pathogen was C. albicans, followed by C. glabrata, C. parapsilosis, C. tropicalis, C. auris, C. krusei, C. lusitaniae, C. inconspicua, C. dubliniensis, C. orthopsilosis, Candida spp. and non-albicans Candida [33-61]. Patient treatment included azole antifungal agents (fluconazole, voriconazole, isavuconazole), echinocandins (caspofungin, anidulafungin, micafungin), and polyenes (amphotericin B, nystatin) [33-35,40,42-44,46-48,51-54,56,59]. It should be noted that nystatin was used for the treatment of a patient with oropharyngeal candidiasis [43]. Despite antifungal treatment, the fatality rate among patients with COVID-19 and candidiasis oscillated between 11 and 100\% [33-61]. 
Table 2. Cases of COVID-19 and candidiasis co-infection.

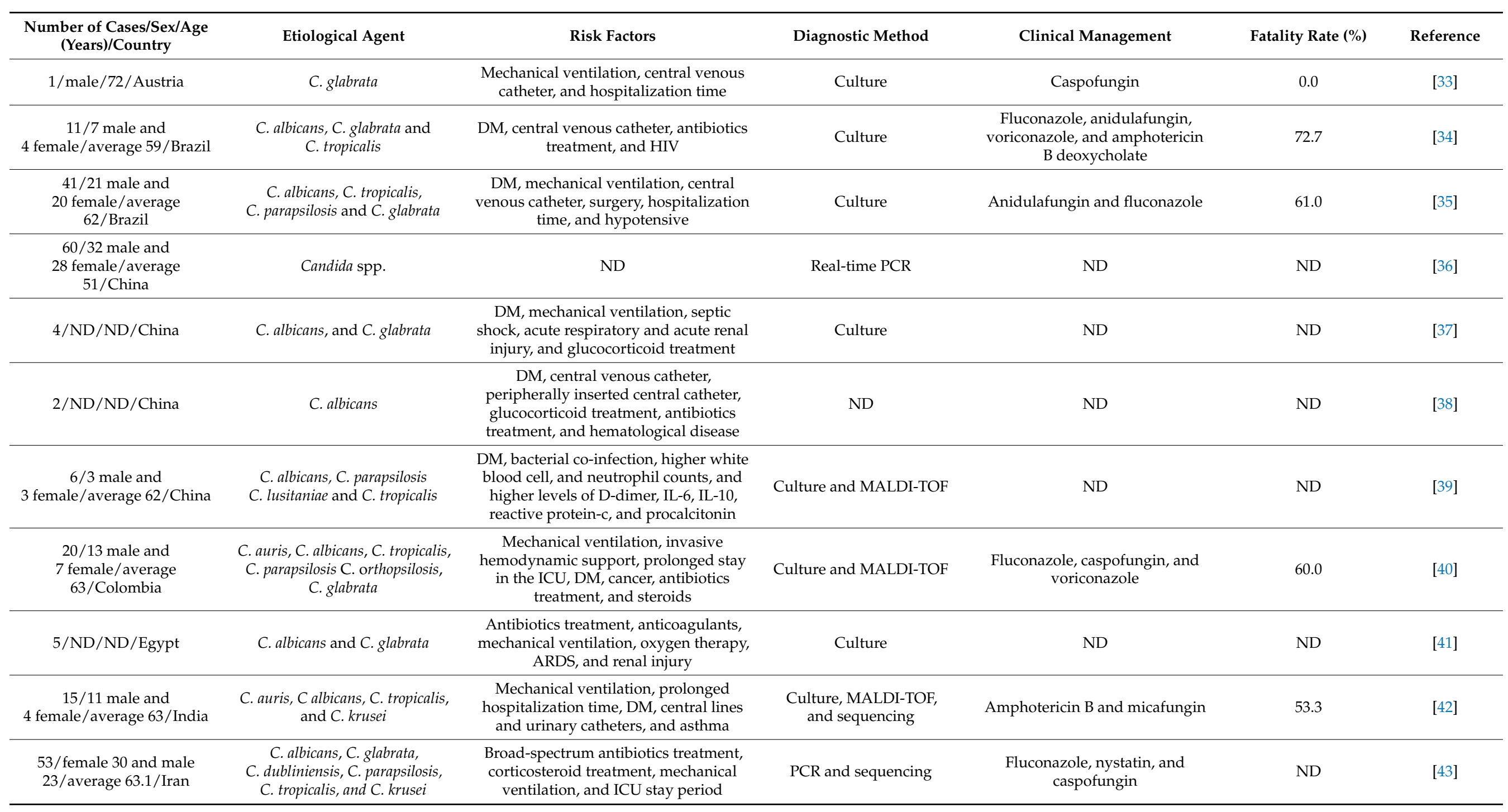


Table 2. Cont.

\begin{tabular}{|c|c|c|c|c|c|c|}
\hline $\begin{array}{c}\text { Number of Cases/Sex/Age } \\
\text { (Years)/Country }\end{array}$ & Etiological Agent & Risk Factors & Diagnostic Method & Clinical Management & Fatality Rate (\%) & Reference \\
\hline $3 /$ male/average $67.6 /$ Italy & $\begin{array}{c}\text { C. albicans, C. parapsilosis and } \\
\text { C. tropicalis }\end{array}$ & $\begin{array}{l}\text { Central venous catheter, parental } \\
\text { nutrition, antibiotics treatment, and } \\
\text { steroids treatment }\end{array}$ & Culture & Caspofungin, and fluconazole & 0.0 & [44] \\
\hline 36/ND/ND/Italy & $\begin{array}{l}\text { C. albicans, C. lusitaniae, } \\
\text { C. glabrata, C. parapsilosis, and } \\
\text { C. inconspicua }\end{array}$ & ND & Culture and MALDI-TOF & ND & ND & [45] \\
\hline 7/ND/ND/Italy & $\begin{array}{l}\text { C. albicans, C. inconspicua and } \\
\text { C. parapsilosis }\end{array}$ & $\begin{array}{l}\text { ICU stay period, mechanical ventilation, } \\
\text { central venous catheter, antibiotics } \\
\text { treatment, and corticosteroids treatment }\end{array}$ & Culture & Echinocandins & ND & [46] \\
\hline 6/ND/ND/Italy & C. auris & $\begin{array}{l}\text { ICU length of stay, broad-spectrum } \\
\text { antibiotics treatment, and asthma }\end{array}$ & $\begin{array}{l}\text { Culture and MALDI-TOF, } \\
\text { sequencing }\end{array}$ & Echinocandins & 50.0 & [47] \\
\hline $1 /$ male/79/Italy & C. glabrata & $\begin{array}{l}\text { Mechanical ventilation, antibiotics } \\
\text { treatment, DM, and surgery }\end{array}$ & Culture and MALDI-TOF & Caspofungin & 100.0 & [48] \\
\hline 3/ND/ND/Italy & $\begin{array}{c}\text { C. albicans, C. parapsilosis and } \\
\text { C. tropicalis }\end{array}$ & $\begin{array}{l}\text { Antibiotics treatment, HIV, cancer, DM, } \\
\text { anti-inflammatory treatment, and } \\
\text { hospital length of stay }\end{array}$ & Culture & ND & ND & [49] \\
\hline $\begin{array}{c}21 / 16 \text { male and } \\
5 \text { female/average } 71 / \text { Italy }\end{array}$ & $\begin{array}{l}\text { C. albicans and non -albicans, } \\
\text { Candida spp. }\end{array}$ & $\begin{array}{l}\text { Cancer, HIV, antibiotics treatment, } \\
\text { parental nutrition, corticosteroid } \\
\text { treatment, DM, ICU length of stay, } \\
\text { central venous catheter, and surgery }\end{array}$ & Culture & ND & 57.1 & [50] \\
\hline $\begin{array}{l}14 / 8 \text { male and } \\
6 \text { female/average } \\
72 / \text { Lebanon }\end{array}$ & C. auris & $\begin{array}{l}\text { Cancer, ICU length of stay, mechanical } \\
\text { ventilation, urinary catheter, central } \\
\text { venous catheter, broad-spectrum } \\
\text { antibiotics treatment, and steroids } \\
\text { treatment }\end{array}$ & Culture and MALDI-TOF & Caspofungin and anidulafungin & 35.7 & [51] \\
\hline $\begin{array}{l}12 / 10 \text { male and } \\
2 \text { female/average } \\
55 / \text { Mexico }\end{array}$ & C. auris and C. glabrata & $\begin{array}{l}\text { Mechanical ventilation, peripherally } \\
\text { inserted central lines, urinary catheter, } \\
\text { asthma, steroids treatment, and } \\
\text { prolonged ICU stay }\end{array}$ & $\begin{array}{l}\text { Culture-MALDI-TOF, } \\
\text { and sequencing }\end{array}$ & $\begin{array}{l}\text { Isavuconazole, anidulafungin, } \\
\text { caspofungin, amphotericin B, } \\
\text { and voriconazole }\end{array}$ & 83.3 & [52] \\
\hline $5 /$ male/average 59/Oman & $\begin{array}{l}\text { C. albicans, C. glabrata and } \\
\text { C. tropicalis }\end{array}$ & $\begin{array}{l}\text { Mechanical ventilation, ICU prolonged } \\
\text { length of stay, broad-spectrum } \\
\text { antibiotics treatment, and central } \\
\text { line catheter }\end{array}$ & Culture and MALDI-TOF & $\begin{array}{l}\text { Amphotericin B, caspofungin, } \\
\text { and voriconazole }\end{array}$ & 60.0 & [53] \\
\hline $1 /$ male/53/Spain & C. albicans & $\begin{array}{l}\text { Mechanical ventilation, corticosteroid } \\
\text { treatment, broad-spectrum antibiotics } \\
\text { treatment, and central venous catheter }\end{array}$ & Culture & Fluconazole & 0.0 & [54] \\
\hline
\end{tabular}


Table 2. Cont

\begin{tabular}{|c|c|c|c|c|c|c|}
\hline $\begin{array}{c}\text { Number of Cases/Sex/Age } \\
\text { (Years)/Country }\end{array}$ & Etiological Agent & Risk Factors & Diagnostic Method & Clinical Management & Fatality Rate (\%) & Reference \\
\hline $3 / \mathrm{ND} / \mathrm{ND} / \mathrm{UK}$ & C. albicans & $\begin{array}{l}\text { Central line, mechanical ventilation, } \\
\text { immunomodulatory therapy, and } \\
\text { broad-spectrum antibiotics treatment }\end{array}$ & Culture and MALDI-TOF & ND & ND & [55] \\
\hline $\begin{array}{l}\text { 17/Ratio male:female was } \\
\text { 2:1/aveage 58/UK }\end{array}$ & C. albicans and C. parapsilosis & $\begin{array}{l}\text { Cancer, corticosteroid treatment, } \\
\text { ventilation support, asthma, DM, and } \\
\text { central venous catheter }\end{array}$ & Culture and MALDI-TOF & $\begin{array}{l}\text { Liposomal amphotericin B, } \\
\text { fluconazole, caspofungin, } \\
\text { and voriconazole }\end{array}$ & 38.5 & [56] \\
\hline $\begin{array}{c}35 / 21 \text { male and } \\
14 \text { female/average } 69 / \text { USA }\end{array}$ & C. auris & $\begin{array}{l}\text { Central venous catheter, mechanical } \\
\text { ventilator, urinary catheter, DM, cancer, } \\
\text { nasogastric and gastric tube }\end{array}$ & Culture & ND & ND & [57] \\
\hline $1 / \mathrm{male} / 54 / \mathrm{USA}$ & C. albicans & Cancer, and mechanical ventilation & Culture & ND & ND & [58] \\
\hline $\begin{array}{c}8 / 4 \text { male and } \\
4 \text { female/average } 63 / \mathrm{USA}\end{array}$ & $\begin{array}{c}\text { C. albicans, C. glabrata, } \\
\text { C. parapsilosis and C. tropicalis }\end{array}$ & $\begin{array}{l}\text { ICU length of stay, mechanical } \\
\text { ventilation, and central venous catheter }\end{array}$ & Culture and MALDI-TOF & Caspofungin and fluconazole & 38.0 & [59] \\
\hline $1 / \mathrm{male} / 46 / \mathrm{USA}$ & C. albicans & $\begin{array}{l}\text { Mechanical ventilation, cancer, } \\
\text { and surgery }\end{array}$ & Culture & ND & 33.0 & [60] \\
\hline $\begin{array}{c}12 / 9 \text { male and } \\
3 \text { female/average } 62 / \mathrm{USA}\end{array}$ & $\begin{array}{l}\text { C. albicans, C. parapsilosis, } \\
\text { C. glabrata, C. tropicalis, and } \\
\text { C. dublinensis }\end{array}$ & $\begin{array}{l}\text { Mechanical ventilation, central venous } \\
\text { catheter, ICU stay, and broad-spectrum } \\
\text { antibiotics treatment }\end{array}$ & Culture and MALDI-TOF & ND & 75.0 & [61] \\
\hline
\end{tabular}




\section{Aspergillosis and COVID-19}

During the first year of the COVID-19 pandemic, 33 articles reporting aspergillosis co-infection in patients with COVID-19 have been published (Table 3). The most frequent causal agent was $A$. fumigatus, followed by $A$. flavus, Aspergillus spp. A. niger, A. terreus, A. lentulus, A. nidulans, A. awamori, A. penicillioides, and A. citrinoterreus $[23,56,62-92]$. The most used diagnostic methods were cultivation, galactomannan and (1,3)- $\beta$-D-glucan detection, MALDI-TOF, histopathology, serological tests, PCR, and sequencing [23,56,62-92]. It should be noted that in some of the A. fumigatus isolates, the TR34/L98H mutation in the Cyp51A gene was detected, which is associated with environmental azole resistance to antifungal agents $[78,83]$. Caspofungin, voriconazole, amphotericin $\mathrm{B}$, anidulafungin, posaconazole, itraconazole, fluconazole or isavuconazole were used in antifungal treatment $[23,56,62-64,66,67,69-72,74,76-82,84-90]$.

The fatality rate in cases of Aspergillus co-infection with SARS-CoV-2 was between $13 \%$ and $100 \%$ [23,56,62-92]. The affected patients were mainly men between 42 and 87 years of age $[23,56,62-92]$. The reported predisposing risk factors for the mycosis progression were diverse, including treatment with corticosteroids or immunosuppressants, hospitalization in the ICU, diabetes mellitus, hypertension, obesity, invasive mechanical ventilation, neoplasms, chronic obstructive pulmonary disease (COPD), asthma, and kidney disease $[23,56,62-92]$. 
Table 3. Cases of COVID-19 and aspergillosis co-infection.

\begin{tabular}{|c|c|c|c|c|c|c|}
\hline $\begin{array}{c}\text { Number of Cases/Sex/Age } \\
\text { (Years)/Country }\end{array}$ & Etiological Agent & Risk Factors & Diagnostic Method & Clinical Management & Fatality Rate (\%) & Reference \\
\hline 1/female/72/China & A. fumigatus & $\begin{array}{l}\text { Leflunomide for rheumatoid } \\
\text { arthritis, Methylprednisolone, } \\
\text { Tocilizumab, and } \\
\text { glucocorticoid treatment }\end{array}$ & $\begin{array}{l}\text { High-performance } \\
\text { sequencing analysis }\end{array}$ & Caspofungin acetate & 0.0 & [23] \\
\hline $\begin{array}{l}\text { 5/male:female ratio } \\
\text { 2.2:1/ Average } \\
\text { 57/United Kingdom }\end{array}$ & A. fumigatus & Solid neoplasm & $\begin{array}{c}\text { AspICU algorithm, } \\
\text { BAL, } \\
\text { culture, } \\
\text { PCR, } \\
\text { BDG, } \\
\text { GM }\end{array}$ & $\begin{array}{c}\text { Voriconazole } \\
\text { caspofungin } \\
\text { liposomal amphotericin B }\end{array}$ & 53.0 & [56] \\
\hline $\begin{array}{l}\text { 14/ND/average } \\
\text { 50.35/Mexico }\end{array}$ & $\begin{array}{l}\text { Aspergillus spp., } \\
\text { A. fumigatus, } \\
\text { A. flavus, } \\
\text { A. niger }\end{array}$ & $\begin{array}{c}\text { Obesity, } \\
\text { DM, } \\
\text { hypertension, } \\
\text { active smoker and } \\
\text { HIV }\end{array}$ & $\begin{array}{l}\text { Culture, } \\
\text { MALDI-TOF, } \\
\text { sGM }\end{array}$ & $\begin{array}{l}\text { Voriconazole, } \\
\text { anidulafungin }\end{array}$ & 57.0 & [62] \\
\hline $\begin{array}{l}\text { 20/ND/elderly/USA } \\
\text { and Spain }\end{array}$ & A. fumigatus & $\begin{array}{l}\text { Severe immunosuppression due to } \\
\text { hematological neoplasm } \\
\text { or transplants, } \\
\text { hypertensionlung disease, } \\
\text { steroid therapy }\end{array}$ & $\begin{array}{l}\text { BAL, } \\
\text { culture, } \\
\text { BDG }\end{array}$ & $\begin{array}{c}\text { Voriconazole, } \\
\text { posaconazole, } \\
\text { liposomal mphotericin B }\end{array}$ & 100.0 & [63] \\
\hline $1 /$ female/74/Netherlands & A. fumigatus & Hospitalization in the ICU & $\begin{array}{l}\text { Culture, } \\
\text { GM, } \\
\text { BDG }\end{array}$ & $\begin{array}{l}\text { Voriconazole, } \\
\text { liposomal amphotericin B, } \\
\text { caspofungin }\end{array}$ & 100.0 & [64] \\
\hline $1 /$ male/71/Brazil & A. penicillioides & $\begin{array}{c}\text { Hypertension } \\
\text { DM, } \\
\text { chronic kidney disease }\end{array}$ & $\begin{array}{c}\text { Histopathology, } \\
\text { GM, Confirmation by } \\
\text { nucleotide sequencing }\end{array}$ & Post-mortem diagnosis & 100.0 & [65] \\
\hline $\begin{array}{c}13 / 11 \text { male and } \\
2 \text { female/average } 54 \text { to } \\
78 / \text { Netherlands }\end{array}$ & A. fumigatus & $\begin{array}{c}\text { Immunosuppression, } \\
\text { ICU, } \\
\text { VMI, } \\
\text { prolonged use of } \\
\text { corticosteroids treatment }\end{array}$ & $\begin{array}{c}\text { BDG, } \\
\text { GM, } \\
\text { Fungal PCR targeting } \\
\text { the Cyp51A gene }\end{array}$ & $\begin{array}{c}\text { Voriconazole, } \\
\text { caspofungin, } \\
\text { liposomal amphotericin B }\end{array}$ & 40.0 to 50.0 & {$[66]$} \\
\hline
\end{tabular}


Table 3. Cont.

\begin{tabular}{|c|c|c|c|c|c|c|}
\hline $\begin{array}{c}\text { Number of Cases/Sex/Age } \\
\text { (Years)/Country }\end{array}$ & Etiological Agent & Risk Factors & Diagnostic Method & Clinical Management & Fatality Rate (\%) & Reference \\
\hline $1 /$ female/66/Australia & A. section Fumigati & $\begin{array}{c}\text { Hypertension, } \\
\text { smoking history, } \\
\text { osteopenia, } \\
\text { Facklamia hominis blood culture and } \\
\text { Escherichia coli urine culture on } \\
\text { admission }\end{array}$ & $\begin{array}{l}\text { Non-bronchoscopic } \\
\text { endotracheal aspirate } \\
\text { with Gram staining }\end{array}$ & Voriconazole & 0.0 & [67] \\
\hline $1 /$ male/ND/Austria & Aspergillus spp. & $\begin{array}{c}\text { Chronic degenerative disease, } \\
\text { neoplasia, } \\
\text { immunosuppression }\end{array}$ & Autopsy & Post-mortem diagnosis & 100.0 & [68] \\
\hline $\begin{array}{c}5 / 3 \text { male and } \\
2 \text { female/average } \\
69 / \text { Pakistan }\end{array}$ & $\begin{array}{l}\text { A. fumigatus, } \\
\text { A. flavus, } \\
\text { A. niger }\end{array}$ & $\begin{array}{c}\text { DM, } \\
\text { high blood pressure }\end{array}$ & $\begin{array}{l}\text { Culture, } \\
\text { IgM, } \\
\text { BDG }\end{array}$ & $\begin{array}{c}\text { Voriconazole, } \\
\text { liposomal amphotericin B }\end{array}$ & 40.0 & [69] \\
\hline $1 /$ male/46/China & A. fumigatus & $\begin{array}{c}\mathrm{DM}, \\
\text { stage } 2 \text { hypertension }\end{array}$ & $\begin{array}{c}\text { Culture, } \\
\text { MALDI-TOF }\end{array}$ & Voriconazole & 0.0 & {$[70]$} \\
\hline $1 /$ female/87/France & Aspergillus spp. & ND & $\begin{array}{l}\text { GM, } \\
\text { ELISA, } \\
\text { Western blot, } \\
\text { PCR }\end{array}$ & Voriconazole & 100.0 & {$[71]$} \\
\hline $1 /$ female/58/Qatar & A. niger, A. terreus & $\begin{array}{c}\text { Diabetic nephropathy, } \\
\text { hypertension, } \\
\text { hyperlipidemia, } \\
\text { chronic hepatitis B infection, } \\
\text { elderly patient }\end{array}$ & Culture & $\begin{array}{c}\text { Anidulafungin, liposomal } \\
\text { amphotericin B, } \\
\text { voriconazole }\end{array}$ & 100.0 & [72] \\
\hline $1 /$ male $/ 74 /$ France & A. fumigatus & $\begin{array}{l}\text { Asymptomatic myelodysplastic } \\
\text { syndrome (hypereosinophilia, with } \\
\text { CD8+ T-cell lymphocytosis), } \\
\text { Hashimoto's thyroiditis, } \\
\text { and hypertension }\end{array}$ & $\begin{array}{l}\text { Culture, } \\
\text { PCR, } \\
\text { BDG, } \\
\text { GM }\end{array}$ & $\begin{array}{l}\text { No antifungal treatment was } \\
\text { initiated due to the rapid } \\
\text { and fatal course in } \\
\text { the patient }\end{array}$ & 100.0 & [73] \\
\hline $1 /$ female/42/Iran & Aspergillus spp. & $\begin{array}{c}\text { Acute myeloid leukemia, } \\
\text { DM }\end{array}$ & $\begin{array}{c}\text { GM, } \\
\text { ELISA for Aspergillus }\end{array}$ & Liposomal amphotericin B & 100.0 & {$[74]$} \\
\hline
\end{tabular}


Table 3. Cont.

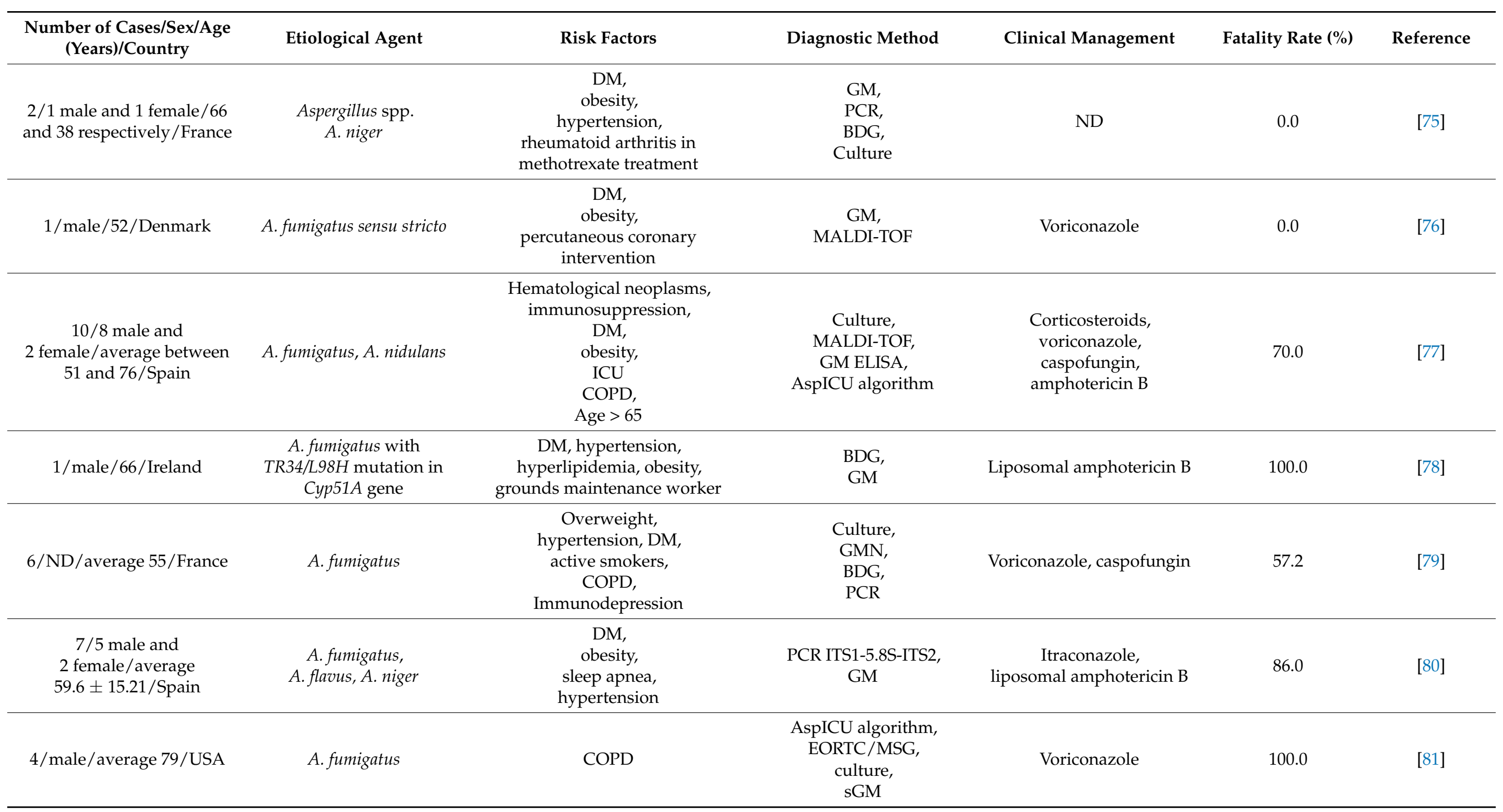


Table 3. Cont.

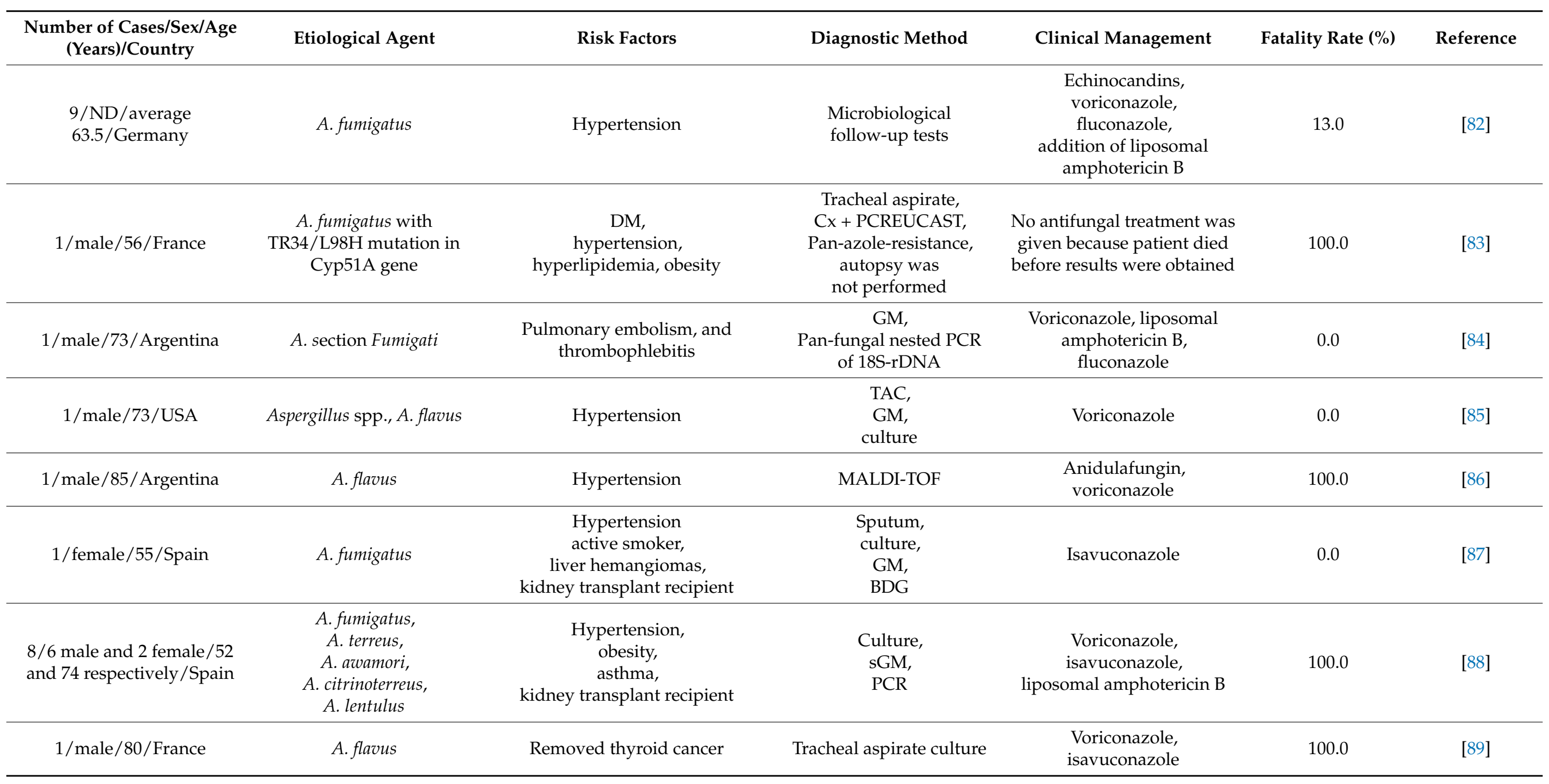


Table 3. Cont.

\begin{tabular}{|c|c|c|c|c|c|c|}
\hline $\begin{array}{c}\text { Number of Cases/Sex/Age } \\
\text { (Years)/Country }\end{array}$ & Etiological Agent & Risk Factors & Diagnostic Method & Clinical Management & Fatality Rate (\%) & Reference \\
\hline $\begin{array}{c}30 / 24 \text { male and } \\
6 \text { female/between } 38 \text { and } 86 \\
\text { respectively/Germany, } \\
\text { France, Netherlands, } \\
\text { Belgium, Italy, Austria }\end{array}$ & $\begin{array}{c}\text { A. fumigatus, } \\
\text { Aspergillus spp. A. flavus }\end{array}$ & $\begin{array}{c}\text { Obesity, } \\
\text { DM, } \\
\text { hypertension, } \\
\text { chronic kidney disease, } \\
\text { hyperlipidemia }\end{array}$ & $\begin{array}{l}\text { Culture + } \\
\text { GM, } \\
\text { sGM, } \\
\text { PCR }\end{array}$ & $\begin{array}{c}\text { Voriconazole, } \\
\text { isavuconazole, } \\
\text { caspofungin, } \\
\text { liposomal amphotericin B }\end{array}$ & 50.0 & [90] \\
\hline $\begin{array}{l}\text { 6/ND/ND/ } \\
\text { United Kingdom }\end{array}$ & A. fumigatus & $\begin{array}{l}\text { COVID-19 requiring hospitalization } \\
\text { in the ICU }\end{array}$ & $\begin{array}{c}\text { Culture, } \\
\text { Microscopy, } \\
\text { GM, } \\
\text { BDG, } \\
\text { PCR } \\
\end{array}$ & ND & ND & [91] \\
\hline $\begin{array}{l}\text { 10/ND/average } \\
62 / \text { Netherlands }\end{array}$ & Aspergillus spp. & & $\begin{array}{c}\text { GM, } \\
\text { PCR, } \\
\text { Culture }\end{array}$ & ND & ND & [92] \\
\hline
\end{tabular}

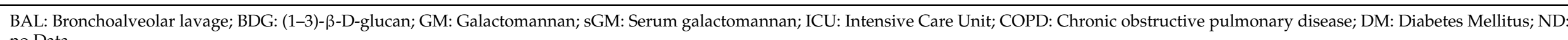
no Data. 


\section{Mucormycosis and COVID-19}

In this study, nine publications of mucormycosis co-infection with COVID-19 were found (Table 4). Except for one case [93], all occurred in men in the age range of 24-86 years [93-101]. The predominant clinical form of mucormycosis was the rhinoorbital, followed by the pulmonary [93-101]. Only one case of each of the gastrointestinal [95] and rhinocerebral conditions was reported [93]. Among the main predisposing factors were diabetes mellitus, ketoacidosis, glucocorticoid use, or broad-spectrum antibiotics. Additional predisposing factors for lung mucormycosis were also reported, such as systemic high blood pressure, end-stage kidney disease, and ischemic cardiomyopathy [93-101]. The mycosis diagnosis was based mainly on histopathological analysis and culture [95-99,101]. In two cases, the clinical picture and the magnetic resonance imaging (MRI) were considered alone [93,94], whereas in one case, PCR and sequencing were used to detect and identify the pathogen [100]. The etiological agents in decreasing order were Mucor spp., Rhizopus microsporus, Rhizopus spp., and Lichteimia spp. [96-100]. In $36 \%$ of cases, the fungus was not identified [93-95,101]. Although the antifungal treatment included amphotericin B and isavuconazole, only $50 \%$ of patients showed clinical improvement $[93,94,96-99,101]$. The fatality rate was $50 \%$ [93-101]. 
Table 4. Cases of COVID-19 and mucormycosis co-infection.

\begin{tabular}{|c|c|c|c|c|c|c|}
\hline $\begin{array}{c}\text { Number of } \\
\text { Cases/Sex/Age } \\
\text { (Years)/Country }\end{array}$ & Etiological Agent & Risk Factors & Diagnostic Method & Clinical Management & Fatality Rate (\%) & Reference \\
\hline $1 /$ male $/ 60 /$ India & Unidentified & $\begin{array}{l}\text { DM, glucocorticoid treatment, } \\
\text { and broad-spectrum } \\
\text { antibiotics treatment }\end{array}$ & Clinical and suggestive MRI & Amphotericin B & 0.0 & [94] \\
\hline 1/male/86/Brazil & Unidentified & $\begin{array}{l}\text { Glucocorticoid treatment and } \\
\text { broad-spectrum } \\
\text { antibiotics treatment }\end{array}$ & $\begin{array}{l}\text { Histopathology, } \\
\text { Gastric ulcer biopsy }\end{array}$ & ND & 0.0 & [95] \\
\hline $1 /$ female/33/USA & Unidentified & Uncontrolled DM & Clinical and suggestive MRI & $\begin{array}{l}\text { Amphotericin B and } \\
\text { sinonasal debridement }\end{array}$ & 0.0 & [93] \\
\hline $1 /$ male/55/India & R. microsporus & $\begin{array}{l}\text { DM, glucocorticoid treatment, } \\
\text { broad-spectrum antibiotics } \\
\text { treatment, systemic high blood } \\
\text { pressure, end-stage kidney } \\
\text { disease, ischemic cardiomyopathy }\end{array}$ & Sputum sample culture & $\begin{array}{l}\text { Liposomal amphotericin B, } \\
\text { upper right lobectomy }\end{array}$ & 100.0 & [96] \\
\hline $1 /$ male/49/USA & Rhizopus spp. & $\begin{array}{c}\text { Glucocorticoid treatment, } \\
\text { broad-spectrum } \\
\text { antibiotics treatment }\end{array}$ & $\begin{array}{c}\text { Histopathology, } \\
\text { Right upper lobe biopsy }\end{array}$ & Amphotericin B & 0.0 & [97] \\
\hline $1 /$ male/24/Mexico & Lichteimia (Absidia) spp. & $\begin{array}{l}\text { Uncontrolled DM, } \\
\text { diabetic ketoacidosis }\end{array}$ & Culture & Amphotericin B & 0.0 & [98] \\
\hline $1 /$ male/66/Italy & Rhizopus spp. & $\begin{array}{l}\text { Broad-spectrum } \\
\text { antibiotics treatment }\end{array}$ & Bronchial aspirate culture & $\begin{array}{c}\text { Liposomal amphotericin } \mathrm{B}, \\
\text { isavuconazole, } \\
\text { thoracocentesis }\end{array}$ & 0.0 & [99] \\
\hline 1/male/53/Austria & R. microsporus & $\begin{array}{l}\text { Neoplasia, } \\
\text { glucocorticoids treatment }\end{array}$ & $\begin{array}{l}\text { dPCR and sequencing, } \\
\text { complete microscopic } \\
\text { autopsy of lung tissue }\end{array}$ & ND & 0.0 & [100] \\
\hline $\begin{array}{l}\text { 6/male/average } \\
60.5 / \text { India }\end{array}$ & $\begin{array}{l}\text { 2-Unidentified and } \\
\text { 4-Mucor spp. }\end{array}$ & $\begin{array}{c}\text { DM, diabetic ketoacidosis, } \\
\text { glucocorticoid treatment, and } \\
\text { uncontrolled DM }\end{array}$ & Culture and histopathology & FESS and amphotericin B & 100.0 & [101] \\
\hline
\end{tabular}

DM: Diabetes mellitus, ND: No data; FESS: Functional endoscopic sinus surgery. 


\section{Endemic Mycoses and COVID-19}

Information on endemic fungal co-infections with SARS-CoV-2 is scarce. Only five cases have been published so far, two of COVID-19 and coccidioidomycosis in California, United States [102,103], and three of COVID-19 and histoplasmosis in Rio Grande, Southern Brazil, and Buenos Aires, Argentina [104-106] (Table 5). Coccidioidomycosis co-infections were caused by C. immitis [102,103]. They occurred in a man and a woman, both 48 years of age, with the main predisposing factor of residing in endemic areas [102,103]. The diagnosis was established with serological test results, and fluconazole was administered as an antifungal treatment. Both patients showed clinical improvement [102,103].

Histoplasmosis co-infections were caused by H. capsulatum and affected two women and one man in the range between 36 and 43 years of age [104-106]. Predisposing factors were HIV with CD4+ count $<200$ cells $/ \mathrm{mm}^{3}$ and residing in endemic areas [104-106]. The diagnosis in these cases was performed through staining methods (Gomori-Grocott, Wright, and Giemsa), blood culture, and antigen detection in urine and serum [104-106]. Antifungal treatment in COVID-19 patients with histoplasmosis was itraconazole and amphotericin B deoxycholate, which noticeably improved patients' clinical state [104-106]. 
Table 5. Cases of COVID-19 and endemic mycosis co-infection.

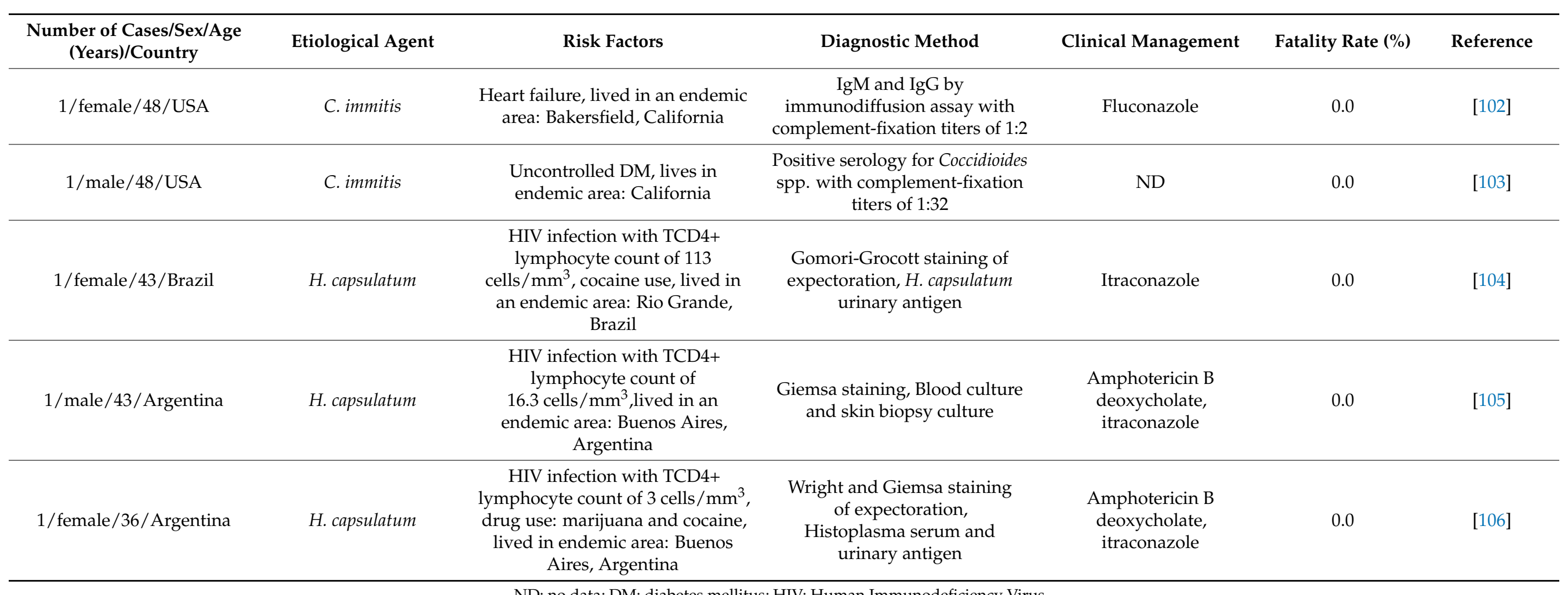

ND: no data; DM: diabetes mellitus; HIV: Human Immunodeficiency Virus. 


\section{Future Challenges of Systemic Mycoses Co-Infections and COVID-19}

To date, there is no specific treatment for patients with COVID-19. However, in severe cases, high-dose systemic glucocorticoids are administered as it has been observed that they improve patient survival. Broad-spectrum antibiotics are also used [96]. The latter, in addition to the specific physiopathologic characteristics of COVID-19, such as the cytokine storm and reduced T-cell levels, favor fungal co-infections $[94,95,101,107]$. However, reports of fungal co-infections in COVID-19 patients are scarce, probably because fungal lung infections, such as pneumocystosis, aspergillosis, histoplasmosis, and coccidioidomycosis, can be mistaken for SARS-CoV-2 infection.

Furthermore, they might be unnoticed because the symptoms in both diseases are very similar, including fever, dry cough, dyspnea, myalgia, and headache $[7,103]$. There are no pathognomonic radiographic or tomographic findings that can differentiate a COVID-19 pneumopathy from a fungal infection [108]. These facts undoubtedly limit proper patient therapeutic management, which can lead to fatal outcomes, as shown by the few reports we present in this work, where the fatality rate ranges from 11 to $100 \%$ (Tables 1-5). This situation poses three new challenges related to the diagnosis of fungal infections that will have to be overcome in the remainder of the pandemic.

In the first challenge, it is crucial that, in the case of evidence of fungal co-infection in COVID-19 patients, the clinical picture is not attributed exclusively to SARS-CoV-2 infection, particularly in severe cases. While many of the secondary infections in these patients are caused by bacteria or viruses, it is vital to not forget about fungi, particularly those with clinical pictures virtually indistinguishable from SARS-CoV-2 pneumonia, like $P$. jirovecii. In this sense, healthcare workers must consider the medical history and epidemiological data, as they may be key to establishing clinical suspicion and directing diagnosis by selecting appropriate laboratory or cabinet tests.

The second challenge is related to diagnostic tests. The conventional tests that identify a fungal pathogen and confirm a mycosis diagnosis have different limitations, such as the time required to obtain a result or the impossibility of determining the fungus at the species level. The latter is utterly important, especially in mycosis caused by different species, particularly from the genera Candida, Aspergillus, and the order Mucorales. It is worth mentioning that new species have been identified, and many species that had not previously been associated with infections in humans are now recognized as pathogenic within these fungal groups. Further, many of these new species may have different susceptibility to the antifungals of choice for mycosis treatment, for example, we can cite C. auris and Aspergillus section Fumigati. While it is true that the limitations of conventional diagnostic tests have been gradually overcome with the development and implementation of different tests, particularly molecular ones, not all tests are available in intrahospital laboratories due to the lack of adequate infrastructure [91].

Diagnosing mycoses with molecular techniques is often complicated because they require trained staff. It is also impractical to routinely analyze multiple samples. The use of PCR and other molecular methods provides limited detection and identification due to the presence of inhibitors in clinical samples. Such inhibitors can lead to underestimating fungus at different levels, from the extraction process to the amplification of nucleic acids. As for antigen detection, it is not always specific as there is potential antigenic crossreactivity, which would prevent fungal identification [109].

The third challenge related to diagnostic tests is sample collection. For example, for COVID-19-associated pulmonary aspergillosis diagnosis, the sample must be collected from a bronchial washing that can generate aerosols representing a source of infection for healthcare personnel $[62,75,110,111]$. Another critical complication in diagnosis is the lack of algorithms and standardized diagnostic methods since the European Organization for Research and Treatment of Cancer (EORTC)/Mycoses Study Group (MSG) criteria are not specific for aspergillosis. For this reason, in an effort to establish a timely diagnosis, the AspICU algorithm for non-immunocompromised patients has been modified. 
Overcoming these challenges will allow identification of cases of co-infections caused by SARS-CoV-2 and fungi, and enable definition of risk factors, affected populations, species distribution, and its antifungal profile.

Treatments reported in the revised literature fail to mention antifungal effectiveness as it is unknown whether the reported mortality was due to the stage of the disease per se or the fungal infection. In addition, treatment depends on the adequate diagnosis, which is complicated, as already mentioned. Thus, by not diagnosing the fungi properly, the correct treatment may not be given, and therefore it may not be effective.

It is important to mention that this work has limitations. This study did not include mycoses that were either reported just once, like fusariosis or caused by fungi that have rarely been associated with human infections, like Saccharomyces cerevisiae. Another limitation is that, unfortunately, not all fungal infections developed in COVID-19 patients have been reported in the literature. It should be noted that most references included in this study come from non-American countries, even though America has been the continent most affected by the pandemic. It is highly likely that fungal co-infections have occurred but have not been detected. It is our hope that the information presented in this study may serve as an alert for health workers to be aware of possible fungal co-infections in COVID-19 patients and the challenges posed by diagnosis. We also hope to remind them of the relevance of establishing acceptable infection control measures, prophylaxis, and adequate antifungal therapies.

Author Contributions: M.G.F.-D.-L. and E.M.-H. designed the study and wrote the manuscript, contributing equally to the accomplishment of the work; R.P.-A., R.H.-C. and P.M.-M. contributed to the writing of the manuscript; M.G.F.-D.-L., E.M.-H., C.R.-C. and R.A. planned, extracted data, wrote, and critically reviewed the manuscript; E.C.-C., E.G.-S. and G.A.-A. wrote, and critically reviewed the manuscript. All authors have read and agreed to the published version of the manuscript.

Funding: This research received no external funding.

Institutional Review Board Statement: Not applicable.

Informed Consent Statement: Not applicable.

Data Availability Statement: Not applicable.

Acknowledgments: Víctor Manuel Espinosa-Hernández from the "Instituto Politécnico Nacional (IPN)" for their assistance in the editing the manuscript. The authors thank Shiftext for language editing and proofreading. M.G.F.-D.-L., R.P.-A., R.H.-C., P.M.-M., G.A.-A. and E.M.-H. thank the Consejo Nacional de Ciencia y Tecnología (Conacyt) for the support to the realization of this article.

Conflicts of Interest: The authors declare no conflict of interest.

\section{References}

1. WHO. WHO Coronavirus (COVID-19) Dashboard. Available online: https://covid19. who.int/ (accessed on 21 March 2021).

2. Huang, C.; Wang, Y.; Li, X.; Ren, L.; Zhao, J.; Hu, Y.; Zhang, L.; Fan, G.; Xu, J.; Gu, X.; et al. Clinical features of patients infected with 2019 novel coronavirus in Wuhan, China. Lancet 2020, 395, 497-506. [CrossRef]

3. Wu, Z.; McGoogan, J.M. Characteristics of and important lessons from the Coronavirus Disease 2019 (COVID-19) outbreak in China: Summary of a report of 72,314 cases from the Chinese Center for Disease Control and Prevention. JAMA 2020, 323, 1239. [CrossRef] [PubMed]

4. Seyed Hosseini, E.; Riahi Kashani, N.; Nikzad, H.; Azadbakht, J.; Hassani Bafrani, H.; Haddad Kashani, H. The novel coronavirus Disease-2019 (COVID-19): Mechanism of action, detection and recent therapeutic strategies. Virology 2020, 551, 1-9. [CrossRef] [PubMed]

5. Tavakolpour, S.; Rakhshandehroo, T.; Wei, E.X.; Rashidian, M. Lymphopenia during the COVID-19 infection: What it shows and what can be learned. Immunol. Lett. 2020, 225, 31-32. [CrossRef] [PubMed]

6. Pemán, J.; Ruiz-Gaitán, A.; García-Vidal, C.; Salavert, M.; Ramírez, P.; Puchades, F.; García-Hita, M.; Alastruey-Izquierdo, A.; Quindós, G. Fungal co-infection in COVID-19 patients: Should we be concerned? Rev. Iberoam. Micol. 2020, 37, 41-46. [CrossRef]

7. Segrelles-Calvo, G.; Araujo, G.R.S.; Frases, S. Systemic mycoses: A potential alert for complications in COVID-19 patients. Future Microbiol. 2020, 15, 1405-1413. [CrossRef]

8. Adalja, A.A.; Sappington, P.L.; Harris, S.P.; Rimmele, T.; Kreit, J.W.; Kellum, J.A.; Boujoukos, A.J. Isolation of Aspergillus in three 2009 H1N1 influenza patients. Influenza Other Resp. Viruses 2011, 5, 225-229. [CrossRef] 
9. García-Vidal, C.; Barba, P.; Arnan, M.; Moreno, A.; Ruiz-Camps, I.; Gudiol, C.; Ayats, J.; Ortí, G.; Carratala, J. Invasive aspergillosis complicating pandemic influenza A (H1N1) infection in severely immunocompromised patients. Clin. Infect. Dis. 2011, 53, e16-e19. [CrossRef]

10. Wauters, J.; Baar, I.; Meersseman, P.; Meersseman, W.; Dams, K.; De Paep, R.; Lagrou, K.; Wilmer, A.; Jorens, P.; Hermans, G. Invasive pulmonary aspergillosis is a frequent complication of critically ill H1N1 patients: A retrospective study. Intensive Care Med. 2012, 38, 1761-1768. [CrossRef]

11. Crum-Cianflone, N. Invasive aspergillosis associated with severe influenza infection. Open Forum. Infect. Dis. 2016, 3, ofw171. [CrossRef] [PubMed]

12. Van de Veerdonk, F.L.; Kolwijck, E.; Lestrade, P.P.A.; Hodiamont, C.J.; Rijnders, B.J.A.; van Paassen, J.; Haas, P.J.; Oliveira Dos Santos, C.; Kampinga, G.A.; Bergmans, D.C.; et al. Influenza-associated aspergillosis in critically ill patients. Am. J. Respir. Crit. Care Med. 2017. [CrossRef]

13. Schauwvlieghe, A.F.A.D.; Rijnders, B.J.A.; Philips, N.; Verwijs, R.; Vanderbeke, L.; Van Tienen, C.; Lagrou, K.; Verweij, P.E.; Van de Veerdonk, F.L.; Gommers, D.; et al. Invasive aspergillosis in patients admitted to the intensive care unit with severe influenza: A retrospective cohort study. Lancet Respir. Med. 2018, 6, 782-792. [CrossRef]

14. Vanderbeke, L.; Spriet, I.; Breynaert, C.; Rijnders, B.J.A.; Verweij, P.E.; Wauters, J. Invasive pulmonary aspergillosis complicating severe influenza: Epidemiology, diagnosis and treatment. Curr. Opin. Infect. Dis. 2018, 31, 471-480. [CrossRef]

15. Immel, S.; Yu, E. Case report: Disseminated aspergillosis complicating influenza. Med. Mycol. Case Rep. 2019, 24, 65-68. [CrossRef] [PubMed]

16. Koehler, P.; Bassetti, M.; Kochanek, M.; Shimabukuro-Vornhagen, A.; Cornely, O.A. Intensive care management of influenzaassociated pulmonary aspergillosis. Clin. Microbiol. Infect. 2019, 25, 1501-1509. [CrossRef]

17. Zou, P.; Wang, C.; Zheng, S.; Guo, F.; Yang, L.; Zhang, Y.; Liu, P.; Shen, Y.; Wang, Y.; Zhang, X.; et al. Invasive pulmonary aspergillosis in adults with avian influenza A (H7N9) pneumonia in China: A retrospective study. J. Infect. Dis. 2020, 221, S193-S197. [CrossRef]

18. Hwang, D.M.; Chamberlain, D.W.; Poutanen, S.M.; Low, D.E.; Asa, S.L.; Butany, J. Pulmonary pathology of severe acute respiratory syndrome in Toronto. Mod. Pathol. 2005, 18, 1-10. [CrossRef] [PubMed]

19. Wang, H.; Ding, Y.; Li, X.; Yang, L.; Zhang, W.; Kang, W. Fatal aspergillosis in a patient with SARS who was treated with corticosteroids. N. Engl. J. Med. 2003, 349, 507-508. [CrossRef]

20. Alanio, A.; Dellière, S.; Voicu, S.; Bretagne, S.; Mégarbane, B. The presence of Pneumocystis jirovecii in critically ill patients with COVID-19. J. Infect. 2020, 82, 84-123. [CrossRef] [PubMed]

21. Bhat, P.; Noval, M.; Doub, J.B.; Heil, E. Concurrent COVID-19 and Pneumocystis jirovecii pneumonia in a severely immunocompromised 25-year-old patient. Int. J. Infect. Dis. 2020, 99, 119-121. [CrossRef]

22. Blaize, M.; Mayaux, J.; Luit, C.E.; Lampros, A.; Fekkar, A. COVID-19-related respiratory failure and lymphopenia do not seem associated with pneumocystosis. Am. J. Respir. Crit. Care Med. 2020, 202, 1734-1736. [CrossRef] [PubMed]

23. Cai, S.; Sun, W.; Li, M.; Dong, L. A complex COVID-19 case with rheumatoid arthritis treated with tocilizumab. Clin. Rheumatol. 2020, 39, 2797-2802. [CrossRef] [PubMed]

24. Coleman, H.; Snell, L.B.; Simons, R.; Douthwaite, S.T.; Lee, M.J. Coronavirus disease 2019 and Pneumocystis jirovecii pneumonia: A diagnostic dilemma in HIV. AIDS 2020, 34, 1258-1260. [CrossRef] [PubMed]

25. De Francesco, M.A.; Alberici, F.; Bossini, N.; Scolari, F.; Pascucci, F.; Tomasoni, G.; Caruso, A. Pneumocystis jirevocii and SARS-CoV-2 co-infection: A common feature in transplant recipients? Vaccines 2020, 8, 544. [CrossRef]

26. Guo, W.; Wang, M.; Ming, F.; Tang, W.; Liang, K. The diagnostic trap occurred in two COVID-19 cases combined Pneumocystis pneumonia in patient with AIDS. Res. Sq. 2020, 10, rs.3.rs-53350.

27. Larzábal, F.J.; Vilela, A.; Brusca, S.; Saluzzi, I.; Ghergo, G.E.; Angiono, M.A. Diagnóstico simultáneo y evolución favorable de infección por Pneumocystis jirovecii, SARS-COV-2 y HIV avanzada. Medicina 2020, 80, 554-556. [PubMed]

28. Mang, S.; Kaddu-Mulindwa, D.; Metz, C.; Becker, A.; Seiler, F.; Smola, S.; Maßmann, A.; Becker, S.L.; Papan, C.; Bals, R.; et al. Pneumocystis jirovecii Pneumonia and SARS-CoV-2 co-infection in newly diagnosed HIV-1 infection. Clin. Infect. Dis. 2020, 72, 1487-1489. [CrossRef]

29. Menon, A.A.; Berg, D.D.; Brea, E.J.; Deutsch, A.J.; Kidia, K.K.; Thurber, E.G.; Polsky, S.B.; Yeh, T.; Duskin, J.A.; Holliday, A.M.; et al. A Case of COVID-19 and Pneumocystis jirovecii coinfection. Am. J. Respir. Crit. Care Med. 2020, 202, 136-138. [CrossRef]

30. Mouren, D.; Goyard, C.; Catherinot, E.; Givel, C.; Chabrol, A.; Tcherakian, C.; Longchampt, E.; Vargaftig, J.; Farfour, E.; Legal, A.; et al. COVID-19 and Pneumocystis jirovecii pneumonia: Back to the basics. Respir. Med. Res. 2021, 79, 100814.

31. Quintana-Ortega, C.; Remesal, A.; Ruiz de Valbuena, M.; de la Serna, O.; Laplaza-González, M.; Álvarez-Rojas, E.; Udaondo, C.; Alcobendas, R.; Murias, S. Fatal outcome of anti-MDA5 juvenile dermatomyositis in a paediatric COVID-19 patient: A case report. Mod. Rheumatol. Case Rep. 2021, 5, 101-107. [CrossRef]

32. Rubiano, C.; Tompkins, K.; Sellers, S.A.; Bramson, B.; Eron, J.; Parr, J.B.; Schranz, A.J. Pneumocystis and severe acute respiratory syndrome coronavirus 2 coinfection: A case report and review of an emerging diagnostic dilemma. Open. Forum. Infect. Dis. 2020, 8, ofaa633. [CrossRef]

33. Seitz, T.; Hoepler, W.; Weseslindtner, L.; Aberle, J.H.; Aberle, S.W.; Puchhammer-Stoeckl, E.; Baumgartner, S.; Traugott, M.; Karolyi, M.; Pawelka, E.; et al. Successful management of the first reported case in Austria of COVID-19 with ARDS. Infection 2020, 48, 647-651. [CrossRef] 
34. Riche, C.V.W.; Cassol, R.; Pasqualotto, A.C. Is the frequency of candidemia increasing in COVID-19 patients receiving corticosteroids? J. Fungi 2020, 6, 286. [CrossRef]

35. Nucci, M.; Barreiros, G.; Guimarães, L.F.; Deriquehem, V.A.S.; Castiñeiras, A.C.; Nouér, S.A. Increased incidence of candidemia in a tertiary care hospital with the COVID-19 pandemic. Mycoses 2021, 64, 152-156. [CrossRef]

36. Zhu, X.; Ge, Y.; Wu, T.; Zhao, K.; Chen, Y.; Wu, B.; Zhu, F.; Zhu, B.; Cui, L. Co-infection with respiratory pathogens among COVID-2019 cases. Virus Res. 2020, 285, 198005. [CrossRef] [PubMed]

37. Chen, N.; Zhou, M.; Dong, X.; Qu, J.; Gong, F.; Han, Y.; Qiu, Y.; Wang, J.; Liu, Y.; Wei, Y.; et al. Epidemiological and clinical characteristics of 99 cases of 2019 novel coronavirus pneumonia in Wuhan, China: A descriptive study. Lancet 2020, 395, 507-513. [CrossRef]

38. He, Y.; Li, W.; Wang, Z.; Chen, H.; Tian, L.; Liu, D. Nosocomial infection among patients with COVID-19: A retrospective data analysis of 918 cases from a single center in Wuhan, China. Infect. Control Hosp. Epidemiol. 2020, 41, 982-983. [CrossRef]

39. Lv, Z.; Cheng, S.; Le, J.; Huang, J.; Feng, L.; Zhang, B.; Li, Y. Clinical characteristics and co-infections of 354 hospitalized patients with COVID-19 in Wuhan, China: A retrospective cohort study. Microbes Infect. 2020, 22, 195-199. [CrossRef] [PubMed]

40. Rodriguez, J.Y.; Le Pape, P.; Lopez, O.; Esquea, K.; Labiosa, A.L.; Alvarez-Moreno, C. Candida auris: A latent threat to critically ill patients with COVID-19. Clin. Infect. Dis. 2020, ciaa1595. [CrossRef]

41. Ramadan, H.K.; Mahmoud, M.A.; Aburahma, M.Z.; Elkhawaga, A.A.; El-Mokhtar, M.A.; Sayed, I.M.; Hosni, A.; Hassany, S.M.; Medhat, M.A. Predictors of severity and co-infection resistance profile in COVID-19 patients: First report from upper Egypt. Infect. Drug Resist 2020, 13, 3409-3422. [CrossRef]

42. Chowdhary, A.; Tarai, B.; Singh, A.; Sharma, A. Multidrug-resistant Candida auris infections in critically Ill coronavirus disease patients, India, April-July 2020. Emerg. Infect. Dis. 2020, 26, 2694-2696. [CrossRef]

43. Salehi, M.; Ahmadikia, K.; Mahmoudi, S.; Kalantari, S.; Jamalimoghadamsiahkali, S.; Izadi, A.; Kord, M.; Dehghan Manshadi, S.A.; Seifi, A.; Ghiasvand, F.; et al. Oropharyngeal candidiasis in hospitalised COVID-19 patients from Iran: Species identification and antifungal susceptibility pattern. Mycoses 2020, 63, 771-778. [CrossRef]

44. Antinori, S.; Bonazzetti, C.; Gubertini, G.; Capetti, A.; Pagani, C.; Morena, V.; Rimoldi, S.; Galimberti, L.; Sarzi-Puttini, P.; Ridolfo, A.L. Tocilizumab for cytokine storm syndrome in COVID-19 pneumonia: An increased risk for candidemia? Autoimmun. Rev. 2020, 19, 102564. [CrossRef] [PubMed]

45. Calderaro, A.; Buttrini, M.; Montecchini, S.; Piccolo, G.; Martinelli, M.; Dell'Anna, M.L.; Di Maio, A.; Arcangeletti, M.C.; Maccari, C.; De Conto, F.; et al. Detection of SARS-CoV-2 and other infectious agents in lower respiratory tract samples belonging to patients admitted to intensive care units of a tertiary-care hospital, located in an epidemic area, during the Italian lockdown. Microorganisms 2021, 9, 185. [CrossRef]

46. Cataldo, M.A.; Tetaj, N.; Selleri, M.; Marchioni, L.; Capone, A.; Caraffa, E.; Caro, A.D.; Petrosillo, N.; INMICOVID-19 Co-Infection Group. Incidence of bacterial and fungal bloodstream infections in COVID-19 patients in intensive care: An alarming "collateral effect". J. Glob. Antimicrob. Resist. 2020, 23, 290-291. [CrossRef] [PubMed]

47. Magnasco, L.; Mikulska, M.; Giacobbe, D.R.; Taramasso, L.; Vena, A.; Dentone, C.; Dettori, S.; Tutino, S.; Labate, L.; Di Pilato, V.; et al. Spread of carbapenem-resistant Gram-negatives and Candida auris during the COVID-19 pandemic in critically Ill patients: One step back in antimicrobial stewardship? Microorganisms 2021, 9, 95. [CrossRef] [PubMed]

48. Posteraro, B.; Torelli, R.; Vella, A.; Leone, P.M.; De Angelis, G.; De Carolis, E.; Ventura, G.; Sanguinetti, M.; Fantoni, M. Panechinocandin-resistant Candida glabrata bloodstream infection complicating COVID-19: A fatal case report. J. Fungi 2020, 6, 163. [CrossRef]

49. Giacobbe, D.R.; Battaglini, D.; Ball, L.; Brunetti, I.; Bruzzone, B.; Codda, G.; Crea, F.; De Maria, A.; Dentone, C.; Di Biagio, A.; et al. Bloodstream infections in critically ill patients with COVID-19. Eur. J. Clin. Investig. 2020, 50, e13319. [CrossRef]

50. Mastrangelo, A.; Germinario, B.N.; Ferrante, M.; Frangi, C.; Li Voti, R.; Muccini, C.; Ripa, M.; COVID-BioB Study Group. Candidemia in COVID-19 patients: Incidence and characteristics in a prospective cohort compared to historical non-COVID-19 controls. Clin. Infect. Dis. 2020, 30, ciaa1594. [CrossRef]

51. Allaw, F.; Kara Zahreddine, N.; Ibrahim, A.; Tannous, J.; Taleb, H.; Bizri, A.R.; Dbaibo, G.; Kanj, S.S. First Candida auris outbreak during a COVID-19 pandemic in a tertiary-care center in Lebanon. Pathogens 2021, 10, 157. [CrossRef] [PubMed]

52. Villanueva-Lozano, H.; Treviño-Rangel, R.J.; González, G.M.; Ramírez-Elizondo, M.T.; Lara-Medrano, R.; Aleman-Bocanegra M.C.; Guajardo-Lara, C.E.; Gaona-Chávez, N.; Castilleja-Leal, F.; Torre-Amione, G.; et al. Outbreak of Candida auris infection in a COVID-19 hospital in Mexico. Clin. Microbiol. Infect. 2021. [CrossRef]

53. Al-Hatmi, A.M.S.; Mohsin, J.; Al-Huraizi, A.; Khamis, F. COVID-19 associated invasive candidiasis. J. Infect. 2021, 82, e45-e46. [CrossRef]

54. Gorospe-Sarasúa, L.; Gallego-Rivera, J.I.; Muñoz-Molina, G.M.; Mirambeaux-Villalona, R.M.; Ajuria-Illarramendi, O.; GonzálezGarcía, A.; Barbolla-Díaz, I. Delayed Candida costochondritis and spondylitis in a post-COVID-19 patient previously treated with corticosteroids, antibiotics, and tocilizumab. Arch. Bronconeumol. 2020. [CrossRef]

55. Hughes, S.; Troise, O.; Donaldson, H.; Mughal, N.; Moore, L. Bacterial and fungal coinfection among hospitalized patients with COVID-19: A retrospective cohort study in a UK secondary-care setting. Clin. Microbiol. Infect. 2020, 26, 1395-1399. [CrossRef]

56. White, P.L.; Dhillon, R.; Cordey, A.; Hughes, H.; Faggian, F.; Soni, S.; Pandey, M.; Whitaker, H.; May, A.; Morgan, M.; et al. A national strategy to diagnose COVID-19 associated invasive fungal disease in the ICU. Clin. Infect. Dis. 2020, ciaa1298. [CrossRef] [PubMed] 
57. Prestel, C.; Anderson, E.; Forsberg, K.; Lyman, M.; de Perio, M.A.; Kuhar, D.; Edwards, K.; Rivera, M.; Shugart, A.; Walters, M.; et al. Candida auris outbreak in a COVID-19 specialty care unit-Florida, July-August 2020. MMWR. Morb. Mortal. Wkly. Rep. 2021, 70, 56-57. [CrossRef]

58. Tafti, D.; Kluckman, M.; Dearborn, M.C.; Hunninghake, J.; Clayton, S. COVID-19 in patients with hematologic-oncologic risk factors: Complications in three patients. Cureus 2020, 12, e12064. [CrossRef]

59. Bishburg, E.; Okoh, A.; Nagarakanti, S.R.; Lindner, M.; Migliore, C.; Patel, P. Fungemia in COVID-19 ICU patients, a single medical center experience. J. Med. Virol. 2020, 2810-2814. [CrossRef]

60. Aesif, S.W.; Bribriesco, A.C.; Yadav, R.; Nugent, S.L.; Zubkus, D.; Tan, C.D.; Mehta, A.C.; Mukhopadhyay, S. Pulmonary pathology of COVID-19 following 8 weeks to 4 months of severe disease: A report of three cases, including one with bilateral lung transplantation. Am. J. Clin. Pathol. 2020, 155, 506-514. [CrossRef] [PubMed]

61. Macauley, P.; Epelbaum, O. Epidemiology and mycology of candidemia in non-oncological medical intensive care unit patients in a tertiary center in the united states: Overall analysis and comparison between non-COVID-19 and COVID-19 cases. Mycoses 2021. [CrossRef] [PubMed]

62. Roman-Montes, C.M.; Martinez-Gamboa, A.; Diaz-Lomelí, P.; Cervantes-Sanchez, A.; Rangel-Cordero, A.; Sifuentes-Osornio, J.; Ponce-de-Leon, A.; Gonzalez-Lara, M.F. Accuracy of galactomannan testing on tracheal aspirates in COVID-19-associated pulmonary aspergillosis. Mycoses 2021, 64, 364-371. [CrossRef] [PubMed]

63. Marr, K.A.; Platt, A.; Tornheim, J.A.; Zhang, S.X.; Datta, K.; Cardozo, C.; García-Vidal, C. Aspergillosis complicating severe coronavirus disease. Emerg. Infect. Dis. 2021, 27, 18-25. [CrossRef]

64. Meijer, E.F.J; Dofferhoand, A.S.M.; Meis, J.F.; Hoiting, O.; Buil, J.B. Azole-resistant COVID-19-associated pulmonary aspergillosis in an immunocompetent host: A case report. J. Fungi 2020, 6, 79. [CrossRef]

65. Santana, M.F.; Pivoto, G.; Alexandre, M.A.A.; Baía-Da-silva, D.C.; da Silva Borboa, M.G.; Almedia Val, F.A.; Brito-Sousa, J.D.; Cardoso-Melo, G.; Monteiro, W.M.; Braga-Souza, J.V.; et al. Confirmed invasive pulmonary aspergillosis and COVID-19: The value of postmortem findings to support antemortem management. Rev. Soc. Bras. Med. Trop. 2020, 53, 1-4. [CrossRef]

66. Meijer, E.F.J.; Dofferhoff, A.S.M.; Hoiting, O.; Meis, J.F. COVID-19-associated pulmonary aspergillosis: A prospective single-center dual case series. Mycoses 2021, 64, 457-464. [CrossRef]

67. Sharma, A.; Hofmeyr, A.; Bansal, A.; Thakkar, D.; Lam, L.; Harrington, Z.; Bhonagiri, D. COVID-19 associated pulmonary aspergillosis (CAPA): An Australian case report. Med. Mycol. Case Rep. 2020, 31, 6-10. [CrossRef] [PubMed]

68. Skok, K.; Vander, K.; Setaffy, L.; Kessler, H.H.; Aberle, S.; Bargfrieder, U.; Trauner, M.; Lax, S.F. COVID-19 autopsies: Procedure, technical aspects and cause of fatal course. Experiences from a single-center. Pathol. Res. Pract. 2021, 217, 153305. [CrossRef] [PubMed]

69. Nasir, N.; Farooqi, J.; Mahmood, S.F.; Jabeen, K. COVID-19-associated pulmonary aspergillosis (CAPA) in patients admitted with severe COVID-19 pneumonia: An observational study from Pakistan. Mycoses 2020, 63, 766-770. [CrossRef]

70. Wu, S.; Yang, S.; Chen, R.; Chen, H.; Xu, Y.; Lin, B. Dynamic Immune Response Profiles and Recovery of a COVID-19 Patient with Coinfection of Aspergillus fumigatus and Other Baseline Diseases: A Case Report. Omi. A. J. Integr. Biol. 2020, 24, 615-618. [CrossRef]

71. Schein, F.; Munoz-Pons, H.; Mahinc, C.; Grange, R.; Cathebras, P.; Flori, P. Fatal aspergillosis complicating severe SARS-CoV-2 infection: A case report. J. Mycol. Med. 2020, 14, 337-339. [CrossRef] [PubMed]

72. Abdalla, S.; Almaslamani, M.A.; Hashim, S.M.; Ibrahim, A.S.; Omrani, A.S. Fatal Coronavirus Disease 2019-associated Pulmonary Aspergillosis; A Report of Two Cases and Review of the Literature. IDCases 2020, 22, e00935. [CrossRef]

73. Blaize, M.; Mayaux, J.; Nabet, C.; Nabet, C.; Lampros, A.; Marcelin, A.G.; Thellier, M.; Piarroux, R.; Demoule, A.; Fekkar, A. Fatal Invasive Aspergillosis and Coronavirus Disease in an Immunocompetent Patient. Emerg. Infect. Dis. 2020, 26, 1636-1637. [CrossRef]

74. Nasri, E.; Shoaei, P.; Vakili, B.; Mirhendi, H.; Sadeghi, S.; Hajiahmadi, S.; Sadeghi, A.; Vaezi, A.; Badali, H.; Fakhim, H. Fatal Invasive Pulmonary Aspergillosis in COVID-19 Patient with Acute Myeloid Leukemia in Iran. Mycopathologia 2020, 185, 1077-1084.

75. Fekkar, A.; Poignon, C.; Blaize, M.; Lampros, A. Fungal infection during COVID-19: Does Aspergillus mean secondary invasive aspergillosis? Am. J. Respir. Crit. Care Med. 2020, 202, 902-903. [CrossRef] [PubMed]

76. Haglund, A.; Christensen, S.; Kristensen, L.; Gertsen, J.B.; Buus, L.; Lausch, K.R. Invasive pulmonary aspergillosis and hyperthermia in an immunocompetent patient with COVID-19. Med. Mycol. Case Rep. 2020, 31, 29-31. [CrossRef]

77. Falces-Romero, I.; Ruiz-Bastián, M.; Díaz-Pollán, B.; Maseda, E.; García-Rodríguez, J. SARS-CoV-2 Working Group. Isolation of Aspergillus spp. in respiratory samples of patients with COVID-19 in a Spanish Tertiary Care Hospital. Mycoses 2020, 63, 1144-1148. [CrossRef] [PubMed]

78. Mohamed, A.; Hassan, T.; Trzos-Grzybowska, M.; Thomas, J.; Quinn, A.; O'Sullivan, M.; Griffin, A.; Rogers, T.R.; Fe-Talento, A. Multi-triazole-resistant Aspergillus fumigatus and SARS-CoV-2 co-infection: A lethal combination. Med. Mycol. Case Rep. 2020, 31, 1-3. [CrossRef]

79. Fekkar, A.; Lampros, A.; Mayaux, J.; Poignon, C.; Demeret, S.; Constantin, J.M.; Mercelin, A.-G.; Monsel, A.; Luyt, C.-E.; Blaize, M. Occurrence of Invasive Pulmonary Fungal Infections in Patients with Severe COVID-19 Admitted to the ICU. Am. J. Respir. Crit. Care Med. 2021, 203, 307-317. [CrossRef] [PubMed] 
80. Segrelles-Calvo, G.; Araújo, G.R.S.; Llopis-Pastor, E.; Carrillo, J.; Hernández-Hernández, M.; Rey, L.; Rodríguez-Melean, N.; Escribano, I.; Antón, E.; Zamarro, C.; et al. Prevalence of opportunistic invasive aspergillosis in COVID-19 patients with severe pneumonia. Mycoses 2021, 64, 144-151. [CrossRef]

81. Mitaka, H.; Perlman, D.C.; Javaid, W.; Salomon, N. Putative invasive pulmonary aspergillosis in critically ill patients with COVID-19: An observational study from New York City. Mycoses 2020, 63, 1368-1372. [CrossRef]

82. Rothe, K.; Feihl, S.; Schneider, J.; Wallnöfer, F.; Wurst, M.; Lukas, M.; Treiber, M.; Lahmer, T.; Heim, M.; Dommasch, M.; et al. Rates of bacterial co-infections and antimicrobial use in COVID-19 patients: A retrospective cohort study in light of antibiotic stewardship. Eur. J. Clin. Microbiol. Infect. Dis. 2020, 2, 1-11. [CrossRef]

83. Ghelfenstein-Ferreira, T.; Saade, A.; Alanio, A.; Bretagne, S.; Araujo de Castro, R.; Hamane, S.; Azoulay, E.; Bredin, S.; Delliére, S. Recovery of a triazole-resistant Aspergillus fumigatus in respiratory specimen of COVID-19 patient in ICU-A case report. Med. Mycol. Case Rep. 2020, 31, 15-18. [CrossRef]

84. Sasoni, N.; Rodriguez-Müller, M.; Posse, G.; González, J.; Leonardelli, F.; Garcia-Effron, G. SARS-CoV-2 and Aspergillus section Fumigati coinfection in an immunocompetent patient treated with corticosteroids. Rev. Iberoam. Micol. 2021, 28, S1130-S1406.

85. Patti, R.K.; Dalsania, N.R.; Somal, N.; Sinha, A.; Mehta, S.; Ghitan, M.; Seneviratne, C.; Kupfer, Y. Subacute Aspergillosis “Fungal Balls" Complicating COVID-19. J. Investig. Med. High Impact. Case Rep. 2020, 8, 3. [CrossRef]

86. Fernandez, N.B.; Caceres, D.H.; Bee, K.D.; Irrazabal, C.; Delgado, G.; Farias, L.; Chiller, T.M.; Verweij, P.E.; Stecher, D. Ventilatorassociated pneumonia involving Aspergillus flavus in a patient with coronavirus disease 2019 (COVID-19) from Argentina. Med. Mycol. Case Rep. 2020, 31, 19-23. [CrossRef] [PubMed]

87. Trujillo, H.; Fernández-Ruiz, M.; Gutiérrez, E.; Sevillano, Á.; Caravaca-Fontán, F.; Morales, E.; López-Medrano, F.; Aguado, J.M.; Praga, M.; Andrés, A. Invasive pulmonary aspergillosis associated with COVID-19 in a kidney transplant recipient. Transpl. Infect. Dis. 2020, 23, e13501. [CrossRef] [PubMed]

88. Machado, M.; Valerio, M.; Álvarez-Uría, A.; Olmedo, M.; Veintimilla, C.; Padilla, B.; De la Villa, S.; Guinea, J.; Escribano, P.; Ruiz-Serrano, M.J.; et al. Invasive pulmonary aspergillosis in the COVID-19 era: An expected new entity. Mycoses 2021, 64, 132-143. [CrossRef] [PubMed]

89. Lai, C.C.; Wang, C.Y.; Hsueh, P.R. Co-infections among patients with COVID-19: The need for combination therapy with non-anti-SARS-CoV-2 agents? J. Microbiol. Immunol. Infect. 2020, 53, 505-512. [CrossRef] [PubMed]

90. Mohamed, A.; Rogers, T.R.; Talento, A.F. COVID-19 associated invasive pulmonary aspergillosis: Diagnostic and therapeutic challenges. J. Fungi 2020, 6, 115. [CrossRef]

91. Borman, A.M.; Palmer, M.D.; Fraser, M.; Patterson, Z.; Mann, C.; Oliver, D.; Linton, C.J.; Gough, M.; Brown, P.; Dzietczyk, A.; et al. COVID-19-associated invasive aspergillosis: Data from the UK national mycology reference laboratory. J. Clin. Microbiol. 2021, 59, e02136-20.

92. Yusuf, E.; Vonk, A.; van den Akker, J.P.C.; Bode, L.; Sips, G.J.; Rijnders, B.J.A.; de Steenwinkel, J.; Verkaik, N.J.; Vogel, M.; van der Eerden, M.; et al. Frequency of Positive Aspergillus Tests in COVID-19 Patients in Comparison to Other Patients with Pulmonary Infections Admitted to the ICU. J. Clin. Microbiol. 2020, 2, 278-320.

93. Werthman-ehrenreich, A. Mucormycosis with orbital compartment syndrome in a patient with COVID-19. Am. J. Emerg. Med. Am. J. Emerg. Med. 2021, 42, e5-e264. [CrossRef]

94. Mehta, S.; Pandey, A. Rhino-Orbital Mucormycosis Associated with COVID-19. Cureus 2020, 12, 10-14. [CrossRef] [PubMed]

95. Do Monte, E.S.; Dos Santos, M.E.L.; Ribeiro, I.B.; De Oliveira Luz, G.; Baba, E.R.; Hirsch, B.S.; Pereora Funari, M.; De Moura, E.G.H. Rare and fatal gastrointestinal mucormycosis (Zygomycosis) in a COVID-19 patient: A case report. Clin. Endosc. 2020, 53, 746-749. [CrossRef] [PubMed]

96. Garg, D.; Muthu, V.; Sehgal, I.S.; Ramachandran, R.; Kaur, H.; Bhalla, A.; Puri, G.D.; Chakrabarti, A.; Agarwal, R. Coronavirus Disease (Covid-19) Associated Mucormycosis (CAM): Case Report and Systematic Review of Literature. Mycopathologia 2021, 1-10. [CrossRef]

97. Placik, D.A.; Taylor, W.L.; Wnuk, N.M. Bronchopleural fistula development in the setting of novel therapies for acute respiratory distress syndrome in SARS-CoV-2 pneumonia. Radiol. Case Rep. 2020, 15, 2378-2381. [CrossRef] [PubMed]

98. Waizel-Haiat, S.; Guerrero-Paz, J.A.; Sanchez-Hurtado, L.; Calleja-Alarcon, S.; Romero-Gutierrez, L. A Case of Fatal Rhino-Orbital Mucormycosis Associated with New Onset Diabetic Ketoacidosis and COVID-19. Cureus 2021, 13. [CrossRef]

99. Pasero, D.; Sanna, S.; Liperi, C.; Piredda, D.; Branca, G.P.; Casadio, L.; Simeo, R.; Buselli, A.; Rizzo, R.; Bussu, F.; et al. A challenging complication following SARS-CoV-2 infection: A case of pulmonary mucormycosis. Infection 2020, 1-6. [CrossRef]

100. Zurl, C.; Hoenigl, M.; Schulz, E.; Hatzl, S.; Gorkiewicz, G.; Krause, R.; Eller, P.; Prattes, J. Autopsy proven pulmonary mucormycosis due to Rhizopus microsporus in a critically Ill COVID-19 patient with underlying hematological malignancy. J. Fungi 2021, 7, 88. [CrossRef]

101. Mrittika, S.; Summeet, L.; Tatyarao, P.L.; Ragini, P.; Santosh, G.H. Mucor in a Viral Land: A Tale of Two Pathogens. Indian J. Opththalmol. 2021, 69, 244-252. [CrossRef]

102. Chang, C.C.; Senining, R.; Kim, J.; Goyal, R. An Acute Pulmonary Coccidioidomycosis Coinfection in a Patient Presenting with Multifocal Pneumonia with COVID-19. J. Investig. Med. High Impact Case Rep. 2020, 8, 4-6. [CrossRef]

103. Shah, A.S.; Heidari, A.; Civelli, V.F.; Sharma, R.; Clark, C.S.; Munoz, A.D.; Ragland, A.S.; Johnson, R.H. The Coincidence of 2 Epidemics, Coccidioidomycosis and SARS-CoV-2: A Case Report. J. Investig. Med. High Impact Case Rep. 2020, 8. [CrossRef] 
104. Basso, R.P.; Poester, V.R.; Benelli, J.L.; Stevens, D.A.; Zogbi, H.E.; da Vasconcellos, I.C.S.; Pasqualotto, A.C.; Xavier, M.O. COVID-19-Associated Histoplasmosis in an AIDS Patient. Mycopathologia 2020, 1. [CrossRef]

105. Bertolini, M.; Mutti, M.F.; Barletta, J.A.E.; Falak, A.; Cuatz, D.; Sisto, A.; Ragusa, M.A.; Fernandez Claros, N.O.; Rolón, M.J. COVID-19 Associated with AIDS-Related Disseminated Histoplasmosis: A Case Report. Int. J. STD AIDS 2020, 31, 1222-1224. [CrossRef] [PubMed]

106. Messina, F.A.; Marin, E.; Caceres, D.H.; Romero, M.; Depardo, R.; Priarone, M.M.; Rey, L.; Vázquez, M.; Verweij, P.E.; Chiller, T.M.; et al. Coronavirus Disease 2019 (Covid-19) in a Patient with Disseminated Histoplasmosis and HIV-A Case Report from Argentina and Literature Review. J. Fungi 2020, 6, 275. [CrossRef] [PubMed]

107. Mrittika, S.; Santosh, G.H.; Namrata, S.; Mahipal, S.S. COVID-19 and Eye: A Review of Ophthalmic Manifestations of COVID-19. Indian J. Opththalmol. 2021, 69, 488-509. [CrossRef]

108. Arenas-Jiménez, J.J.; Plasencia-Martínez, J.M.; García-Garrigós, E. When pneumonia is not COVID-19 Cuando la neumonía no es COVID-19]. Radiología 2021, 63, 180-192. [CrossRef]

109. Pfaller, M.A. Molecular approaches to diagnosing and managing infectious diseases: Practicality and costs. Emerg. Infect. Dis. 2001, 7, 312-318. [CrossRef] [PubMed]

110. Hoenigl, M. Invasive Fungal Disease Complicating Coronavirus Disease 2019: When It Rains, it pours. Clin. Infect. Dis. 2020, ciaa1342, 1-4. [CrossRef] [PubMed]

111. Arastehfar, A.; Carvalho, A.; van de Veerdonk, F.L.; Jenks, J.D.; Koehler, P.; Krause, R.; Cornely, O.A.; Perlín, D.S.; Lass-Flörl, C.; Hoenigl, M.; et al. COVID-19 associated pulmonary aspergillosis (CAPA)-From immunology to treatment. J. Fungi 2020, 6, 91. [CrossRef] [PubMed] 